\title{
LA NATURALEZA DE LA EXPANSIÓN ALDEANA DURANTE EL FORMATIVO TARDÍO EN LA CUENCA DE ATACAMA
}

\author{
THE NATURE OF VILLAGE EXPANSION DURING THE LATE \\ FORMATIVE PERIOD IN THE ATACAMA BASIN
}

\author{
Lautaro Núñez*
}

\begin{abstract}
La implantación hortícola de los oasis piemontanos de la cuenca del Salar de Atacama comenzó antes de los 700 años a.C. de acuerdo al registro cronoestratigráfico de maíz durante la fase Tilocalar del Formativo Temprano (1.400 - 400 a.C.). Las prácticas propiamente agrícolas extensivas se habrían consolidado durante las fases posteriores al Formativo Temprano, esto es, desde los 400 a.C. a los 600 d.C. a través de asentamientos complejos datados por $\mathrm{C}^{14}$ en los oasis piemontanos: Tulor-1 (380 a.C. - 200 d.C.) y Coyo-Aldea (660 - 995 d.C.). Se propone que para acceder a la producción ganadera derivada de la fase Tilocalar, poco adaptable a los oasis cálidos, durante el Formativo Tardío se controlaron las vegas del salar, quebradas intermedias y alta puna, a través de un régimen trashumántico complementario, conducido esta vez desde la cabecera sociopolítica de los oasis de San Pedro de Atacama. El registro de siete asentamientos formativos tardíos datados por $\mathrm{C}^{14}$ en los extremos periféricos de la cuenca de Atacama, asociados a quebradas estrechas esencialmente pastoralistas (Puripica y Tulán), dan cuenta de un proceso expansivo orientado a equilibrar la productividad agraria y pecuaria. En este sentido se propone que la ocupación post Tilocalar del hinterland forrajero ocurrió a través de la fundación de aldeas que comparten similitudes arquitectónicas, artefactuales, ambientales y cronológicas, irradiadas desde el núcleo de San Pedro de Atacama.
\end{abstract}

Palabras claves: oasis de San Pedro de Atacama, período Formativo, expansión aldeana, complementariedad agroganadera.

Horticulture in the foothill oases of the Atacama Basin began before 700 B.C. according to the chronostratigraphic record of maize, which first appeared during the Tilocalar Phase of the Early Formative Period (1400 - 400 B.C.). Extensive farming activities must have been consolidated during the phases following the Early Formative Period, that is, from about 0 to 500 A.D., as seen in complex, ${ }^{14}$ C-dated settlements in the foothill oases: Tulor-1 (380 B.C. - 200 A.D.) and Coyo-Aldea (660 - 995 A.D.). I propose that in order to access the herding production derived from the Tilocalar Phase, which was little adapted to the warm oases, during the Late Formative Period the inhabitants of the region controlled the plains of the salar, the intermediate canyons, and the high puna through a complementary transhumant regime. At this time, sociopolitical leadership of the system was situated in the oases of San Pedro de Atacama. The record of seven ${ }^{14} \mathrm{C}$-dated settlements in the extreme peripheries of the Atacama Basin, associated with narrow, essentially pastoral canyons (Puripica and Tulán), demonstrates an expansive process aimed at balancing farming and herding productivity. In this sense, I propose that the post-Tilocalar occupation of the grassland (forrajero) hinterland occurred through the foundation of villages that shared similarities in architecture, artifacts, environments, and chronologies, spreading from the nuclear community at San Pedro de Atacama.

Key words: San Pedro de Atacama oasis; Formative Period; village expansion; agropastoral complementarity.

Los avances del conocimiento cronológico y artefactual en torno al período Formativo Tardío (FTA) en la cuenca de Atacama y del Loa han permitido esclarecer contextos, tecnologías, ritualidad y un cierto grado de contactos a nivel distribucional (Agüero et al. 1995; Ayala y Uribe 2003; Ayala et al. 1995; Benavente 1982; Castro et al. 1994; Llagostera et al. 1984; Llagostera y Costa 1999; Noel 1992; Sinclaire et al. 1997; Tarragó 1968, 1989; Varela et al. 1993). No obstante, aún es sen- sible el déficit de información sobre sus asentamientos y estilos de vida (Lynch y Núñez 1994; Núñez 1992, 1995, 1999; Martínez 1989), toda vez que las investigaciones sobre funebria siguen dominando hasta ahora la literatura especializada (Berenguer et al. 1980; Tarragó 1968).

Los estudios comparativos del Formativo han enfatizado el rol de la cerámica para definir procesos generales de diferenciación. Por lo mismo, es necesario identificar mejor cómo se distribuye la

* Instituto de Investigaciones Arqueológicas y Museo, Universidad Católica del Norte, San Pedro de Atacama, Chile. lautanunez@netline.cl 
diversa materialidad artefactual intramuro y en redes de asentamientos, en relación al orden productivo y social manejado por las elites sociopolíticas locales. La identificación y estudio de asentamientos aldeanos en las quebradas de Puripica y Tulán permiten visualizar desde los extremos de la cuenca de Atacama, un aspecto ocupacional poco conocido que guarda relación con la multiplicación de aldeas ubicadas en la mayoría de los pisos forrajeros marginales del transecto alta puna-quebradas intermedias-oasis piemontanos-salar de Atacama, cuya naturaleza de su dependencia sociopolítica económica constituye la problemática expuesta.

Observada la cuenca de Atacama entre Puripica y Tilomonte, se identifican procesos de intensificación productiva con escalas variables de logros agrarios y pecuarios, de acuerdo a las condiciones naturales estimuladas por las variaciones altitudinales. En esta dirección, la distribución geográfica de las aldeas, puestas en secuencia, deberían presentar indicadores culturales y ecofácticos diferentes, en relación a la articulación de producciones pertinentes al piso ecológico electo. Esta aproximación metodológica tendiente a identificar relaciones interasentamientos, con muestreos de poblados representativos se deriva de prospecciones sistemáticas y de pruebas cronoestratigráficas para definir posteriormente propuestas de excavaciones extensivas. En general, las excavaciones en asentamientos permiten someter a prueba las tipologías artefactuales provenientes de contextos funerarios, como así también esclarecer las asociaciones entre sí, otorgando información de valor homotaxial y societaria, al definir patrones constructivos, domésticos, laborales y ritualísticos no selectivos, útiles para reconstituciones de procesos sociales más integradores. En este sentido, más que una secuencia de tiestos cerámicos se espera que los residuos de viviendas (p. ej., restos de innovaciones tecnológicas y subsistenciales), registrados en diversas áreas de actividades y concentraciones demográficas, podrían explicitar procesos culturales e identificar, a su vez, relaciones entre control de producción y diferenciación social (Chapman 1991; Mathers 1986).

Si bien es cierto que la sola localización de los asentamientos no permite observaciones determinantes sobre sus orientaciones económicas, una vez conocidos sus contextos residenciales y laborales es posible entender mejor su fijación en el paisaje social y productivo. Desde esta perspectiva la aproximación cronológica es clave, como instrumento de secuencia, en donde se medirán los cambios y procesos productivos desde una aproximación artefactual-ecofactual.

Los estudios de patrones de asentamientos debidamente cronologizados han realizado aportes sustanciales, con una debida incorporación de patrones de vida, conductas habitacionales y formatos arquitectónicos, poniendo énfasis en la diversificación espacial y locacional intra y extra sitios. Sus aplicaciones en unidades espaciales concretas han sido oportunas, de acuerdo a una: "lectura social de los asentamientos" (Lull 1983:451), para la comprensión de las relaciones sociales y productivas desde una visión espacial "macro" (reconstitución del paisaje), que transite a otra "semimicro" que configura el proceso de reorganización de las ocupaciones hasta alcanzar el análisis "micro" a nivel de las unidades domésticas. Estas aproximaciones metodológicas implícitas en los estudios habitacionales son adecuadas para evaluar el proceso de reproducción económica en relación al desarrollo de las fuerzas productivas, ligadas a la emergencia de desigualdad económica y sus repercusiones (clases) e impactos en la estructura social (estratificación). En efecto, desde una arqueología aldeana es posible medir las transformaciones de la comunidad (p. ej., mayor división de clases), y esto pasa por la gestión del eje político, donde se ejerce y favorece un mayor control directo de las fuerzas internas de trabajo y del régimen de circulación de productos locales y foráneos.

Se debería esperar en este espacio económicamente significativo de los oasis de San Pedro de Atacama el desarrollo de elites al interior de un proceso de intensificación, capaz de generar innovaciones tecnológicas y acceso a más recursos con mayores concentraciones demográficas y complejidad sociopolíticas a nivel de asentamientos-ejes y/o cabeceras (Chapman 1991; Núñez y Dillehay 1979). Este proceso habría estimulado e innovado el incremento de las actividades a nivel intramuro, en las unidades domésticas, ampliando el tamaño de las comunidades locales e irradiando patrones culturales y económicos a nivel de una escala regional amplia (p. ej., distribución de estilos artesanales y arquitectónicos homólogos), constituyendo una red de asentamientos dependientes de la cabecera de los oasis referidos. De acuerdo a lo anterior, se espera que en los oasis no sólo ocurri- 
rían logros productivos especializados y consolidación de rango social, sino una adecuada organización espacial capaz de equilibrar la producción pastoralista, agraria y minera (Molina 1983; Núñez 1995; Núñez et al. 2002). Así, la propagación de las prácticas agrarias a través de la cuenca de Atacama debió ocurrir principalmente desde los oasis de San Pedro de Atacama, dadas sus condiciones naturales, bajo el hinterland forrajero correspondiente al espacio pecuario altoandino complementario (Gilman y Thornes 1985; Núñez 1995).

De acuerdo a las condiciones geográficas y productivas acotadas a lo largo de la cuenca de Atacama, se puede esclarecer que el área ocupada se limitaba entre el río San Pedro de Atacama-Vilama y sus afluentes hasta el río Tulán en el extremo sur del salar (Figura 1). A lo largo de esta ex- tensión se ha concentrado la mayor frecuencia y magnitud de asentamientos (Le Paige 1963; Hernández 1999), donde se destaca precisamente la cabecera de mayor crecimiento demográfico y aldeano en los oasis de San Pedro de Atacama, con evidencias de un mayor espacio de uso agrario y forestal. Se trata de suelos más útiles en términos de agricultura y concentración aldeana, donde se multiplicaron los procesos de innovaciones tecnológicas, como el incremento de prácticas de molienda, regadío canalizado, incremento minero-metalúrgico, mayor producción artesanal (especialización de oficios), dando lugar a niveles productivos más estables, en aldeas de mayor complejidad, asociadas a un inédito escenario de nuevos ritos funerarios. Por otra parte, la emergencia de un eje sociopolítico en estos oasis piemontanos implicó, junto

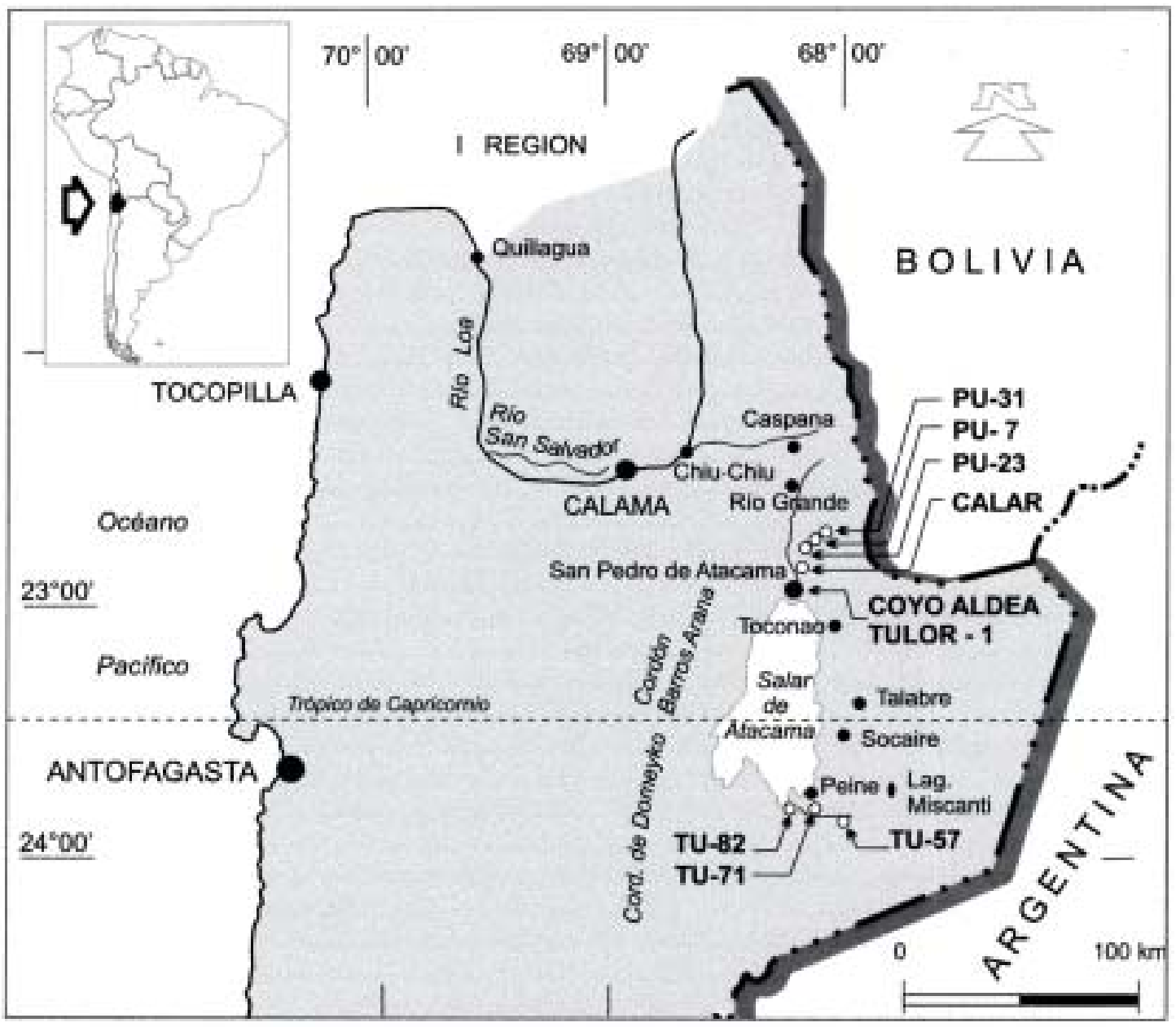

Figura 1. Ubicación de sitios citados en el texto.

Location of sites cited in the text. 
a la notable concentración poblacional, una mayor intensidad en el manejo de la producción de excedentes y control de fuerza de trabajo. La intensificación económica se habría sustentado precisamente en una red de asentamientos del FTA, dispersos a través de una comarca acotada políticamente, desde este núcleo agrario establecido en los oasis de San Pedro de Atacama.

Los datos más consistentes indican que la mayor concentración poblacional en estos oasis habrían creado las condiciones para un original proceso local del desarrollo del FTA con particularidades culturales, económicas y políticas de base agraria (Tarragó 1989). No obstante, la ampliación del proceso de intensificación productiva, contrajo cambios sociales que dieron cuenta precisamente de la necesidad de ampliar la base económica, a través de la expansión pecuaria hacia los enclaves marginales. Esta situación extendió los límites demográficos a través del desplazamiento de grupos hacia los bordes septentrionales, orientales y meridionales de los oasis agrarios, incrementándose sensiblemente la capacidad de carga ganadera.

Las respuestas socioculturales vinculadas con el proceso de intensificación de la producción pecuaria debería implicar, en consecuencia, la implantación gradual de aldeas y tecnologías para el incremento de la ganadería de llamas, en espacios con forraje disponible en todos los enclaves posibles del entorno de los oasis de San Pedro de Atacama. En esta dirección, el manejo de espacios forrajeros marginales orientados al incremento de bienes de subsistencia complementarios, habría exigido de la fundación de asentamientos y estancias involucrados con el uso de tierras con recursos de agua y forraje en áreas alejadas de los centros agrarios, generando posiblemente un mayor grado de complejidad socioproductiva y cultural, como las prácticas de intercambio, más explotación minero-metalúrgico de estatus y mayor crecimiento de redes caravaneras, acorde a la marginalidad espacial de la elite local con respecto a otras áreas vecinas de mayor significado demográfico (Chapman 1991; Núñez et al. 2004; Tarragó 1989).

\section{Las Prestigiosas Cabeceras Agrarias de los Oasis de San Pedro de Atacama}

En la cuenca de Atacama se han llevado a cabo escasas excavaciones en asentamientos aislados del
FTA, desconociéndose sus relaciones con el proceso local y/o macrorregional, como si se tratase de entidades ocupacionales independientes, capaces de valorizarse en sí mismas (Llagostera et al. 1984; Orellana 1988-9; Serracino 1976). La carencia de prospecciones y excavaciones en asentamientos de distintas fases (Hernández 1999; Le Paige 1963; Noel 1992) no ha permitido disponer hasta ahora de suficientes contextos cronoestratigráficos específicos, dándose la paradoja de contar con más dataciones $\mathrm{C}^{14}$ en aquellos asentamientos más tempranos pertenecientes al período Arcaico (Núñez et al. 1999). Recientemente se han presentado los primeros intentos de identificación de fases, variaciones de patrones de asentamientos en términos cronológico-radiocarbónicos y contextuales a lo largo del transecto Tulán-salar de Atacama (Núñez 1995) y patrones de locaciones con inferencias cronológicas derivadas no de los propios asentamientos, sino de la secuencia funeraria de los ayllus de San Pedro de Atacama (Agüero et al. 2003; Llagostera y Costa 1999).

Excavaciones de asentamientos del FTA se han iniciado positivamente en torno al río Vilama cerca de los oasis de San Pedro de Atacama (Carolina Agüero, comunicación personal 2004).

\section{La aldea de Calar}

Se ha reconocido la aldea de Calar en la terraza alta del río Vilama, a unos $15 \mathrm{~km}$ al NE de San Pedro de Atacama (Le Paige 1963; Orellana19889). Se trata de una ocupación del orden de los 2.000 $\mathrm{m}^{2}$ con 34 unidades domésticas semicirculares de los cuales ca. 15 estructuras serían habitaciones socavadas de 4 a 4,5 m. Las estructuras se ordenan en un semicírculo alrededor de un patio amurallado con posterioridad, donde se excavó un cementerio con 25 cuerpos decúbito lateral asociado a innovaciones formativas como la posición encuclillada (Le Paige 1963; Orellana 1988-9).

El patrón de asentamiento de Calar sería contemporáneo con las aldeas de Tulor tanto en térmi-

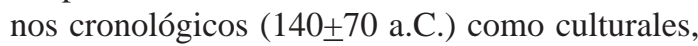
aunque podría ser aún más temprano asociado a: alfarería alisada gris con antiplástico de grandes granos de cuarzo y mica, incluyendo fragmentos craquelados, tiestos pulidos grises y negros, conchas del Pacífico, industria microlítica (perforadores), palas, manos, puntas pedunculadas con aletas, raspadores y cuchillos, componentes que 
caracterizan tanto al FTA como a eventos aún más tempranos. Los pisos habitacionales se caracterizan por la presencia de fogones, huecos de postes y bolsones socavados para cocinas y/o almacenamiento. Estos rasgos son típicos para el FTA asociados a cerámica de la tradición de San Pedro de Atacama, incluyendo contactos con caravanas trasandinas portadoras de tiestos tempranos grabados San Francisco y los policromos de Vaquerias (Orellana 1988-9).

\section{La aldea Tulor-1}

El área del desagüe del río San Pedro de Atacama en el borde norte del salar de Atacama fue prospectada por Le Paige (1993), dando cuenta de 12 asentamientos dispersos con más de 100 recintos circulares, donde se ha destacado el sitio clásico Tulor-1, de carácter más centralizado de unos $4.000 \mathrm{~m}^{2}$ de ocupación; donde destacan 22 estructuras circulares semisubterráneas aglutinadas, asociadas a almacenaje adjunto, al interior de un muro perimetral. La carencia de rocas locales y la disposición de arcilla y aguas corrientes estimularon el uso de grandes adobones irregulares útiles para la construcción de grandes cabañas estructuradas (diámetro de hasta $9 \mathrm{~m}$ ), unidas por pasadizos internos con cabezales de muros visibles con alturas promedio del orden de los 1,9 m, cubiertos por depósitos de dunas (Llagostera et al. 1984). Un indicador constructivo es el carácter curvado al interior de los muros constituyendo techos con posibles cubiertas de barro, sustentados por postes empotrados en el piso, donde destacan socavados para cocinas y almacenaje. Las dataciones $\mathrm{C}^{14}$ más coherentes se han considerado entre los 380 a.C. a los 65 d.C. (Berenguer et al. 1980; Llagostera et al. 1984), asociadas a las fases cerámicas temprana y media: Toconao, Sequitor, Quitor y Coyo. En efecto, se han advertido aquí los inicios de los tiestos negros pulidos clásicos de la tradición local, hasta culminar con la familia negra pulida con su más variada representación, en contacto con tiestos intrusivos trasandinos: San Francisco Negro Grabado, Vaquerías, Tebenquiche y Ciénaga (Llagostera et al. 1984).

Se ha planteado que la ubicación de Tulor-1 guardaría relación con el uso agrario por riego de inundación en la desembocadura del río (horticultura), siguiendo el modelo de otros asentamientos formativos tarapaqueños asociados al apoyo de la recolección forestal (Llagostera et al. 1984; Núñez 1974, 1982), poniendo énfasis en la intensificación de cultivos maiceros en una cota relativamente baja y adecuada del orden de los $2.200 \mathrm{msm}$. A diferencia de Calar ( $2.700 \mathrm{msm}$ ) con recursos pecuarios y agrarios combinados, en Tulor-1 el tono agrario habría sido efectivamente más determinante de acuerdo a los límites cálidos para la crianza de camélidos (Figura 1).

Se ha propuesto que el abandono de Tulor-1 se debería al avance de dunas, a raíz de un régimen de sequía, estimulando el replegamiento de las ocupaciones FTA hacia aguas arriba, paralelo al río San Pedro (Llagostera et al. 1984). Un patrón similar a otra escala se ha planteado para la quebrada de Tarapacá en torno a sociedades formativas tardías y posteriores (Núñez 1978). Al respecto, los estudios cruzados por aproximaciones entre arqueología y paleoclima, de los últimos 2.000 años, son escasos, pero estimulantes en términos de entender el impacto de los eventos áridos (Grosjean 2002). Al revisar la literatura sobre cambio climático entre el altiplano y los espacios de adaptación puneña, se reconocen serias dificultades para correlacionar eventos húmedos y áridos en relación a ocupaciones humanas, especialmente en lo concerniente al desierto de Atacama, al interior de la problemática "Pequeña Edad del Hielo" (Grosjean 2002). Las extrapolaciones de reconstrucciones paleoclimáticas de un territorio a otro, de corta o larga distancia, entre secuencias temporales incompletas no son válidas para establecer analogías entre clima y variación demográfica y ocupacional, ni menos para asociar orientaciones económicas (agricultura), tal como se ha planteado en relación al "Período Cálido Medieval" para el noroeste argentino (Sayago et al. 2001, 2002). Fuera de dudas, el análisis multidisciplinario de base geocientífica es necesario en el mismo ámbito arqueológico examinado (Núñez et al. 1997). Con estos antecedentes y siguiendo esta precaución, se podría sugerir que hay cierto consenso en que los eventos más áridos ocurrieron entre los 850-1.310 d.C., en un marco definitivamente postformativo. En este sentido, sólo es posible admitir que antes de los 850 d.C. se habrían desarrollado eventos posiblemente más húmedos (Grosjean 2002), estos eventos favorables habrían incrementado la producción pecuaria. La definición de estas reconstrucciones locales, aún no precisadas en los oasis de San Pedro de Atacama, son de máxima prioridad para entender el tema que 
relaciona a los procesos de colonización y expansión en relación al manejo de recursos (Chapman 1991; Gilman y Thornes 1985). Los estudios orientados a determinar cambios climáticos y variaciones ambientales (p. ej., eventos húmedo/seco) son indispensables para identificar patrones de subsistencia y dinámica de poblaciones: reducción versus expansión demográfica (Abbot et al. 1997), incluyendo respuestas de superación de crisis de aridez con más creatividad sociopolítica. En esta dirección, el incremento de las labores pecuarias puede considerarse como un medio eficaz para lograr más diversidad y estabilidad en un territorio desértico con recursos frágiles o poco predecibles, estimuladas en parte por el desarrollo de mayor humedad antes de los 850 a.C. Es decir, si las sequías coartan los procesos productivos y la circulación de excedentes, las elites se desarticularían a no ser que intensifiquen, como en este caso, los recursos pecuarios y bienes de prestigio para mantener el manejo del poder.

\section{La aldea Coyo}

Se ha identificado en cotas algo más altas de Tulor-1 uno de los complejos aldeanos más densos de los oasis de San Pedro de Atacama, en torno al ayllu de Coyo (Hernández 1999; Le Paige 1963; Noel 1992), compuesto de al menos cuatro sitios estructurados y aglomerados (Llagostera y Costa 1999). Aquí se ha estudiado el yacimiento CoyoAldea, sometido a intensa deflación, con una ocupación multicomponente superficial con más de cien mil restos de cerámica, líticos, fogones, depósitos expuestos y restos óseos a lo largo de 8.000 $\mathrm{m}^{2}$, asociado a estructuras circulares y restos de un muro perimetral al oeste, todo construido en adobones parecidos a los usados en Tulor-1 (Graffan 1995; Stovel 1998). Las excavaciones de prueba en el sector noroeste han demostrado que la ocupación es exclusivamente local, sin interferencia de componentes Tiwanaku, con labores especializadas agrarias y minero-metalúrgica, asociadas a excedentes de bienes metálicos vinculados con tráfico de bienes de estatus (Graffan 1995). Se cuenta con dos dataciones $\mathrm{C}^{14}$ entre 650-995 d.C., aunque no se han cronometrado los inicios de ocupación en otros sectores de la aldea, donde se advierten tanto indicadores artefactuales y constructivos (p. ej., recintos rectangulares), que transitan desde el FTA a estadios posteriores (Figura 1).
Debe considerarse que, junto a la complejidad cultural y arquitectónica de sólo los yacimientos datados $\mathrm{C}^{14}$ aquí revisados, se extendieron en los oasis de San Pedro de Atacama a través de los $16.000 \mathrm{~m}^{2}$ de ocupación aldeana, en un rango de tiempo del orden de los 140 a.C. a los 650 d.C. y en un espacio interaldeano de no más de $20 \mathrm{~km}$. Fuera de dudas, se está en presencia de un locus FTA que constituyó precisamente una cabecera agraria de prestigio regional.

El desarrollo aldeano del FTA en estos oasis (Calar, Tulor y Coyo-Aldea), dada su relación cronológica, habrían derivado de la fase anterior Tilocalar, de acuerdo a ciertos indicadores, aún en estudio, y que tienen que ver con la transferencia de tradiciones previas como la alfarera: tiestos delgados monocromos pulidos y bruñidos, grises-negroscafé gruesos pulidos y alisados, revestidos, craquelados, con desgrasantes gruesos. Se suma la tradición arquitectónica arcaico-formativa temprana y asentamientos aglomerados, con estructuras subcirculares, bloques verticales empotrados y el manejo especializado de molienda y caza: puntas pedunculadas con aletas, asociadas al uso de fauna no doméstica, tradición de faenamiento a través del uso compartido de implementos expeditivos, además de raederas, cuchillos, raspadores y notable tradición minero-metalúrgica a nivel de bienes excedentarios de estatus: cobre, oro y conchas del Pacífico y del piedemonte yungueño, incluyendo una alta presencia de microperforadores asociados a excedentes de cuentas líticas y de conchas (Núñez 1992, 1999; Núñez et al. 2005).

Es posible que desde los asentamientos-ejes FTA de carácter agrario-minero-metalúrgico de los oasis de San Pedro de Atacama se haya accedido no sólo hacia los extremos sur y norte de la cuenca, sino, además, hacia la vertiente trasandina, a raíz de la presencia de aldeas con recintos circulares y atributos culturales y cronológicos, sincrónicos y homólogos, tal como se han identificado en la quebrada del Toro (Raffino 1973) y cerca del paso de Jama (María Fernández Distel, comunicación personal, 1992).

\section{Asentamientos Pecuarios Complementarios a las Cabeceras de los Oasis de San Pedro de Atacama}

A continuación se informa de los asentamientos localizados en las quebradas de Puripica y Tulán, con recursos de agua estable, orientados tanto 
en el pasado como en el presente con la explotación pastoralista, en relación a sus vínculos de dependencia con las elites de los oasis atacameños.

\section{Quebrada Puripica, Puripica-31 (Sector A)}

Se trata de una ocupación localizada en el borde NE de los oasis de San Pedro de Atacama (3.000 $\mathrm{msm}$ ) en la pendiente (debris), apegada al borde sur de la quebrada, desde el pie vertical del barranco ignimbrítico hasta los depósitos fluviales sobre el curso del río. Cubre un espacio aproximado de ca. $900 \mathrm{~m}^{2}$ (Figura 1). El sitio se separó en un Sector A o superior, donde se observaron refugios al pie del acantilado (16 $\mathrm{m}^{2}$ de ocupación dispersa), uno de éstos fue excavado bajo el código PU-31. La prueba-1 $(150 \times 150 \mathrm{~cm})$ se corresponde con un depósito estratigráfico (ver Perfil A-A' en Figuras 2 y 3), compuesto por cuatro niveles sucesivos: Estrato I depósito con fogón superficial en matriz de concreciones y rodados pequeños semiestéril con bolsones de sedimentos compactos. Estrato II depósito fértil con restos vegetales y fogón lenticular en la base, de donde proviene la datación $\mathrm{C}^{14}$ ( $310 \pm 70$ d.C.). Estrato III lente estéril de concreciones y rodados. Estrato IV depósito de ceniza (los estratos III y IV no presentan materialidad cultural). En la base se observó un socavado para ampliar el refugio, caracterizado por escasos re- gistros culturales. No obstante, el E-II representa un clímax ocupacional en el entorno de un fogón en semicubeta, con una estricta asociación entre la datación $\mathrm{C}^{14}$ y concentración de rocas, huesos de camélidos, núcleo lítico, pala plaquiforme, carbón, cerámica, maíz y algarrobo. En la prueba-1 se recuperaron 398 evidencias culturales y naturales, correspondiente a lítico 59 unidades; cerámico 108 unidades; misceláneo 98 unidades; óseo 134 unidades (ver Anexo 1). Esta prueba permitió muestrear las actividades realizadas bajo refugios, con alta visibilidad sobre la quebrada. Se considera que el depósito es unicomponente y que los estratos I y II son representativos de eventos FTA. El espacio más útil se dedicó a labores de cocina, mientras que la presencia de coprolitos humanos y de llamas, además de leña y carbones, son señales del traslado de estos materiales al refugio para la preparación de fogones. Los artefactos líticos localizados en la periferia, guardan relación con funciones de corte y raído, con formatos expeditivos, algunos tallados allí mismo desde nódulos, núcleos y preformas, asociados a abundante desecho de talla (obsidiana y basalto en lo principal). La presencia de tres manos apunta a acciones complementarias al consumo in situ. Por otra parte, el registro de puntas de proyectil pedunculadas, indicaría cacerías locales; y pala lítica para fines hortícolas y/o preparación de canales y obras mineras. Dada la notable

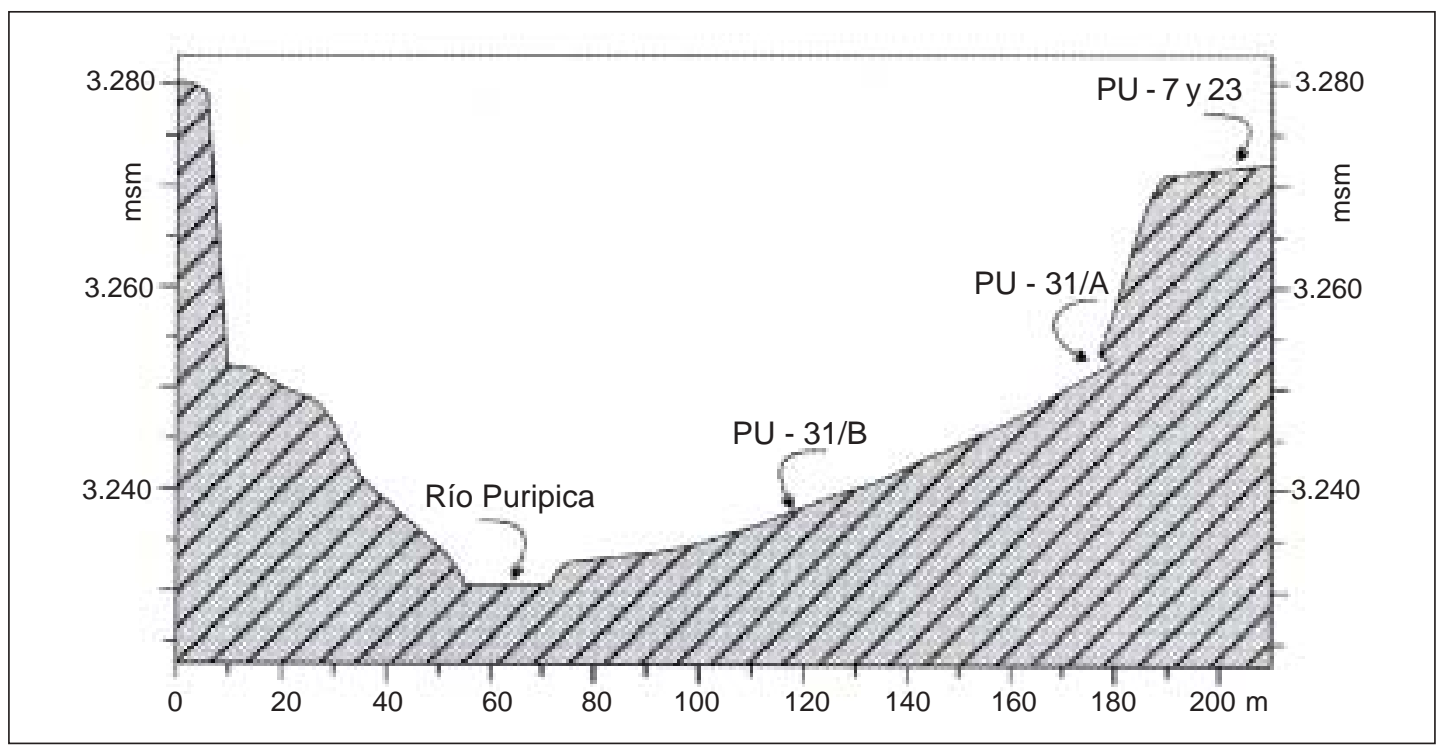

Figura 2. Perfil con la ubicación de los sitios Puripica-31/A-B, Puripica-7 y Puripica-23.

Profile with the location of the sites Puripica-31/A-B, Puripica-7 and Puripica-23. 


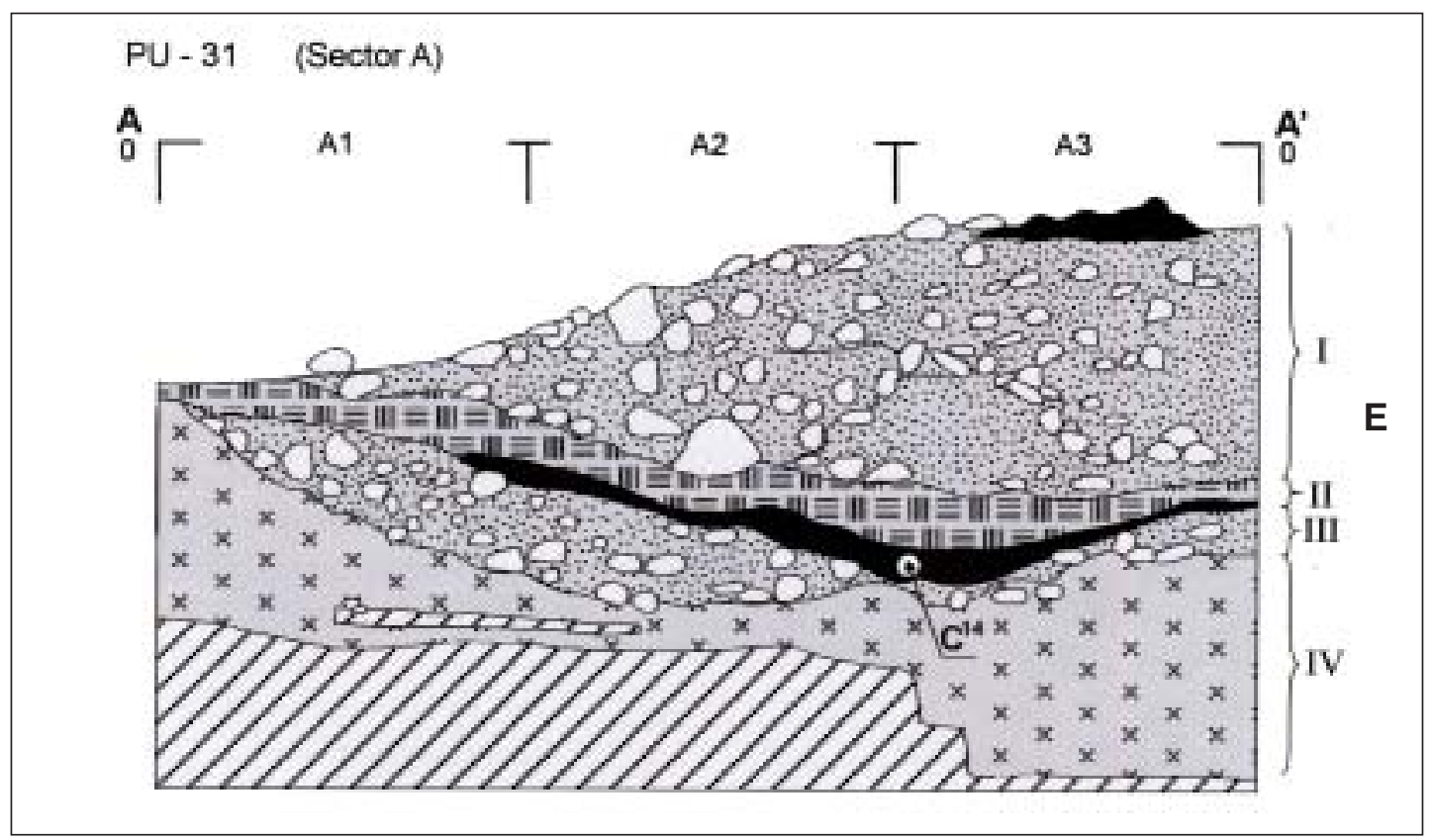

Figura 3. Perfil de la prueba cronoestratigráfica del sitio Puripica 31-A con indicación del muestreo radiocarbónico. Profile of the chronostratigraphic test at the Puripica 31-A site with radiocarbon samples marked.

estrechez de esta quebrada, se debería asumir que las prácticas agrarias eran limitadas al consumo local, a través de técnicas más bien hortícolas. La constatación de 11 restos de maíces quemados da cuenta de estos cultivos a nivel FTA, asociados directamente a la datación $\mathrm{C}^{14}$. Por otro lado, la alta frecuencia de coprolitos de llamas, evidencia la labor pecuaria a lo largo del fondo forrajero de la quebrada, esto es, una combinación posiblemente más ganadera que agraria.

La presencia de una lámina de toba Tulán (raspador) sugiere conexiones con otras comunidades formativas del extremo sur de la cuenca de Atacama, toda vez que los artefactos más comunes se elaboraron con lascas de uso expeditivo, logradas de canteras locales. $\mathrm{Al}$ respecto, el total de las rocas usadas representa una interesante gradación de mayor a menor popularidad: obsidiana, basalto, sílice, calcedonia, cuarzo, toba Tulán, cristal de roca, granito. Es decir, habría una preferencia cultural por el uso de vidrios volcánicos logrados desde el piso altoandino, a raíz de su mejor calidad con respecto a los localizados bajo los $3.500 \mathrm{msm}$, a pesar de contar con abundante recurso basáltico local. Por otro lado, la presencia de semillas de algarrobo demuestra inequívocamente el desplazamiento hacia los oasis piemontanos (San Pedro de
Atacama). Estos indicios de movilidad se correlacionarían con el manejo de circuitos trashumánticos ganaderos, paralelo al acceso a materia prima y alimentos extralocales.

En cuanto a la cerámica, la presencia de fragmentos café y negro pulido exterior y restos de negro bruñido, a través de los estratos I y II, y en parte del depósito inferior o fogón, dan cuenta de la persistencia de la tradición pulida y monocroma formativa derivada de los oasis de San Pedro de Atacama.

En la prueba 1 se registraron, además, 134 restos óseos. Aquellos localizados en el E-I o superior se observaron muy meteorizados y blanqueados por eventos de exposición. Sin embargo, en el E-II y III la conservación es comparativamente mejor, constatándose huesos largos y planos en su mayoría, algunos con marcas puntiformes asignables a la intervención de cánidos o félidos. De acuerdo a su determinación taxonómica la explotación de camélidos es dominante $(96 \%)$ seguida de escasos roedores (4\%). En todos los estratos sólo se reconocieron escasos restos consumidos: Lama guanicoe y L. glama, mientras que los roedores no quemados asociados al fogón se consideran intrusivos. Los camélidos ingresados se corresponderían con un espécimen adulto y otro menor de unos 
34 meses. La mayoría de estos desechos se advierten quemados y fragmentados, arrojándose al fogón para su descarte. Se habrían preferido presas de partes bajas, algunas delanteras y otras de unidades de más alto rendimiento, junto a especímenes salvajes y domésticos, asociados a la dieta maicera. Tal como se ha planteado para los Andes Centrales, habría aquí una coexistencia de labores de caza y pastoreo (Wheeler et al. 1977), hecho que precisamente caracteriza a los eventos formativos tempranos (fase Tilocalar, Núñez et al. 2005). Puesto que no se ha definido una relación artefactual entre los sectores A y B del sitio PU31 , el contexto datado $\mathrm{C}^{14}$ no presenta indicadores más tempranos a su datación, es decir, no se observan marcadores de la fase Tilocalar correspondiente al Formativo Temprano.

\section{Puripica-31 (Sector B)}

Para discutir la cronología de este sector se debe plantear el proceso de evolución del paleopaisaje local. En efecto, se ha descrito una secuencia de campamentos arcaicos y sedimentos aluviales entre los 5.000-4.000 a.p., con episodios asociados a una paleolaguna represada y domesticación de camélidos en la confluencia de quebrada Seca con quebrada de Puripica (Núñez et al. 1999). Precisamente, en este mismo ecorrefugio se han identificado los asentamientos formativos instalados aquí una vez que ocurrió el desagüe lacustre (Figura 2). Este evento geomorfológico se ha datado sobre turbas en el mismo sector de las ocupaciones arcaicas y formativas por los 3.430 a 3.110 a.p. incluyendo otra muestra similar $\mathrm{C}^{14}$ aguas abajo, fechada a los 2.185 a.p., de modo que las ocupaciones formativas tempranas no pudieron ocupar la quebrada antes de los 3.430 a.p. En este sentido es posible que, tanto la fase temprana Tilocalar (3.200-2.400 a.p./1.200-900 a.C.) como otros eventos formativos posteriores, pudieron ocupar este locus de recursos favorables inmediatamente después del límite máximo de 3.430 a.p. Es decir, se propone que el Sector B podría tratarse de una ocupación Tilocalar más temprana que los refugios altos localizados en la cota más alta como el referido y datado en PU-31 (Sector A).

El sitio PU-31 (Sector B) es un campamento, al parecer, parcialmente estructurado con terraplenes de grandes bloques y recintos abatidos a lo largo de unos $900 \mathrm{~m}^{2}$, localizado en la pendiente que desciende desde el refugio datado al pie del acantilado junto a la confluencia de quebrada Seca y el río Puripica. En la superficie se han identificado marcadores que ratifican su filiación formativa temprana: fogones expuestos y abundantes restos de manos y grandes morteros de hueco extendido, incluyendo un bloque inmueble con morteros múltiples, alta frecuencia de desecho de talla de obsidiana, palas, puntas pedunculadas de proyectiles, cerámica modelada, bordes en "coma", cubiletes de piedra pómez, tiestos negro pulidos y bruñidos. Un gran fragmento de un cubilete de roca volcánica, similar al espécimen grabado y ofrendado en el templete de Tulán (TU-54), asegura su correlación con la fase Tilocalar, incluyendo fragmentos rojos (trazados de franjas paralelas) que recuerda a estilos policromos formativos del noroeste argentino (Vaquerías).

El análisis de la cerámica superficial, derivada de un muestreo lineal N-S por el centro del yacimiento, dió cuenta de 89 fragmentos con presencia de tiestos monocromos alisados y pulidos correspondiente a las fase Sequitor y Quitor (Tarragó 1989). En relación al material lítico, se constató la aplicación de microperforadores líticos para horadar y reparar tiestos fragmentados, pero aún no es posible asegurar si el carácter fino de la perforación los vincularía con la tradición formativa temprana Tilocalar (Núñez 1992; Anexo 1). El desecho de percusión de nódulos grandes de obsidiana no local, además de los artefactos terminados, implican conexiones con el piso altoandino aledaño. Este índice de alta movilidad, a través de todo el transecto quebrada Tulán-alta puna, reafirmaría la naturaleza dinámica de las ocupaciones FTA en las quebradas intermedias. Este atributo parece caracterizar a estas ocupaciones pastoralistas a raíz de la combinación armónica entre crianza y horticultura en estos suelos tan limitantes para la expansión agraria.

De acuerdo a la datación del cubilete grabado en el templete de Tulán por los 700-600 a.C. y tiestos de la fase Sequitor, esta ocupación pudo ser una expresión del final de la fase Tilocalar (700400 a.C.). Se habría organizado su asentamiento junto a las vegas del río Puripica, para explotar más cercanamente los recursos ganaderos y hortícolas, situándose inmediatamente sobre la línea máxima de inundación, es decir, lo suficiente para controlar sus actividades pastoralistas. De hecho, es el único sitio formativo ubicado bajo la línea de la 
alta planicie, donde se fijarán posteriormente los asentamientos FTA. ¿Cuál es la naturaleza de esta diferencia ocupacional tan contrastada? En tanto esta ocupación pertenecería a la fase Tilocalar su mayor dependencia al pastoralismo debió ser dominante, configurando un patrón de asentamiento más adosado a los espacios de manutención de llamas, dentro de la quebrada (Figura 2).

\section{Puripica-7}

Este asentamiento se ubica sobre la planicie de un espolón ignimbrítico que se introduce y domina la quebrada de Puripica y desciende a Quebrada Seca en el sector de confluencia. Se trata de un conjunto de ocho recintos levemente separados con tendencia a formatos circulares, a los cuales se le han adosado bodegas (ca. $1.050 \mathrm{~m}^{2}$ de ocupación). Los muros varían entre 30 a $100 \mathrm{~cm}$ de espesor y diámetros entre 3 a $8 \mathrm{~m}$, destacándose un gran corral de ca. $20 \mathrm{~m}$ de diámetro (Figuras 2 y 4). El recinto de la excavación de prueba representa el tamaño mayor del orden de los $8 \mathrm{~m}$ de diámetro. El acceso ocurre por la banda sur, junto al acantilado, marcado por un muro periférico ubicado en el borde alto del barranco, donde se constató un taller de talla lítica. Se muestreó un transecto lineal por el desarrollo más longitudinal del sitio, permitiéndose identificar fragmentos cerámicos formativos tardíos relacionados con la tradición de San Pedro de Atacama: café y plomo pulidos, incluyendo componentes Negro Pulido Clásico y algunos intrusivos como el policromo Vaquerías y un modelado Candelaria (?). Por otra parte, la presencia de tiestos Dupont y Ayquina podría hipotetizar reocupaciones vinculadas con eventos del Desarrollo Regional Tardío. Son comunes los morteros de hueco extendido y huesos de camélidos asociados a cuentas de crisocola. Llama la atención la alta frecuencia de azurita y atacamita a lo largo del sitio, en especial, en un sector nuclear donde aflora la ignimbrítica de un modo planiforme, constituyendo un área de molienda de mineral de cobre (Anexo 1).

De acuerdo a los materiales de superficie, se hacen presentes puntas pedunculadas talladas in situ, dada la ubicación de un taller lítico y del registro de desecho de percusión, preformas y láminas trasladadas al sitio. La alta frecuencia de mineral de cobre tanto para labores de fundición como para la confección de bienes de estatus (p. ej., cri-

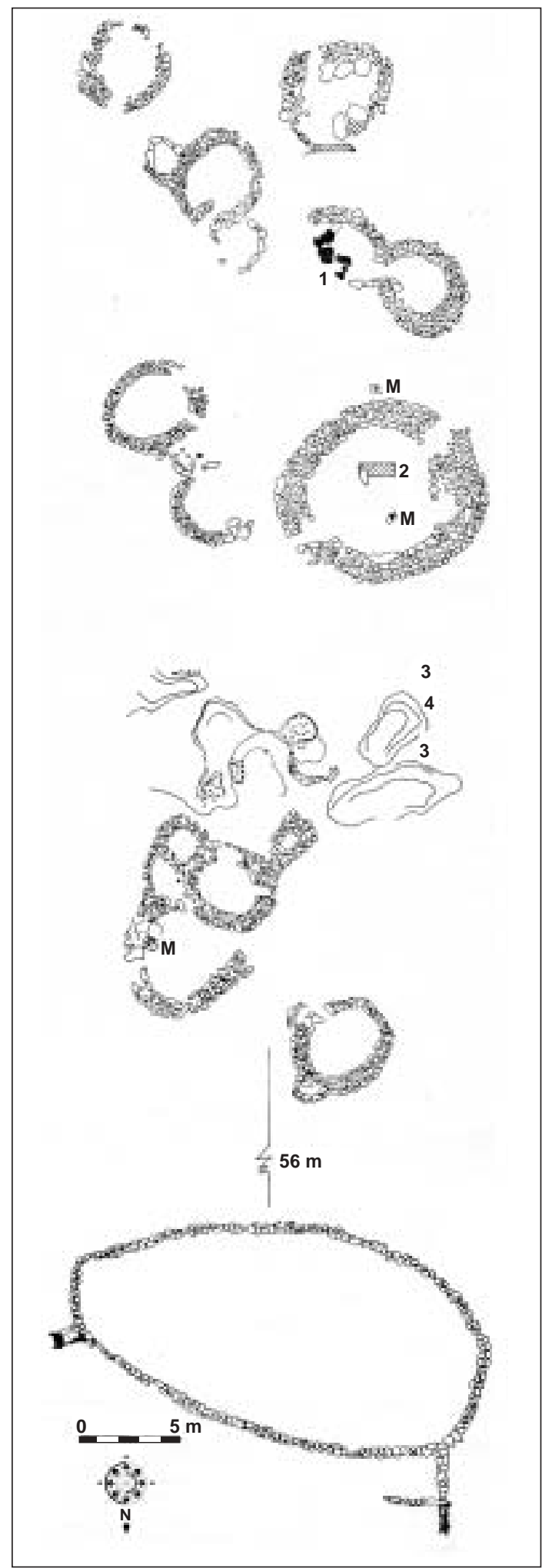

Figura 4. Planta de la aldea Puripica-7. Plan of Puripica-7 village. 
socola y calizas) caracteriza la alta producción de cuentas en el sitio, lo cual incluye el uso de martillos expeditivos, para eliminar la ganga adherida al mineral más azulado, constituyendo talleres para la preparación de bienes jerárquicos. Aunque no es posible asegurarlo, la alta presencia de palas podría vincularse con la extracción de minerales cupríferos y/o preparación de obras hidráulicas no datadas (Carrasco 2002; Núñez et al. 2003). Entre los artefactos líticos sólo seis se corresponden con el recurso obsidiana logrado del piso altoandino; el resto se ha obtenido de las canteras locales y de minas aún no precisadas. De ser correcta la sincronía entre el registro de conchas del Pacífico y la datación $\mathrm{C}^{14}$ se podría interpretar que existían contactos entre el piso altoandino y el Pacífico, movilidad de larga distancia que caracteriza a estos asentamientos FTA como aquellos del período Formativo Temprano.

Del derrumbe de un muro expuesto provienen un metapodio, mandíbula y máxila de un probable Lama glama, de acuerdo a las evidencias dentarias. Según la erupción y desgaste dentario, se correspondería con un individuo adulto (4-10 años). Estos registros se asocian a cuentas de collar de gran factura e indican actividades de crianza local y consumo de camélidos de avanzada edad.

\section{Excavación de prueba (test-1)}

La excavación de prueba se realizó en el interior del recinto $\mathrm{N}^{\circ} 1$, en el sector oriental, a unos $150 \mathrm{~cm}$ del borde intramuro, a través de una calicata del orden de 100x60 cm, con un espesor de ocupación entre los 15-25 cm, hasta desaparecer el registro cultural a los $25 \mathrm{~cm}$ de profundidad. El depósito es un fogón generalizado dispuesto sobre una base de sedimento claro-estéril. No se advierte diferenciación deposicional, de tal modo que podría considerarse como un solo evento estratigráfico (Anexo 1).

En el nivel superior se observaron intrusiones dada la presencia de coprolitos de bóvidos; sin embargo, los niveles medios e inferiores presentan los mejores indicadores del depósito. Es el caso de la presencia continua de partículas de crisocola asociadas a huesos de camélidos. Este registro podría sugerir el desarrollo de labores mineras tanto para la fundición de cobre como de plata (presencia de lámina), lo cual significaría un manejo minero-metalúrgico especializado, hecho que carac- terizaría al FTA. Estas actividades se asociarían a crianzas de camélidos a juzgar por la presencia de huesos y de concentraciones de coprolitos de llamas (nivel 10-15). La presencia de cuentas confirma el énfasis entre la concentración de materias primas cupríferas y la producción de bienes ritualísticos.

Los artefactos líticos son esencialmente expeditivos, observándose cierta tendencia a un dominio de talla lítica derivado de obsidiana foránea. Estas evidencias confirmarían la tendencia a utilizar vidrios volcánicos para artefactos modelados con técnicas de presión bi y monofacial, de carácter menos expeditivo, tal como se advierte entre las puntas de proyectiles pedunculadas. Sólo siete fragmentos de cerámica se recuperaron en los niveles excavados; sin embargo, éstos son suficientemente consistentes para ayudar a la cronología relativa del sitio. Se trata de tiestos vinculados con la tradición Negra Pulida fina del oasis de San Pedro de Atacama, acordes con la datación. Una muestra de carbón obtenida en el nivel medio se fechó en $320 \pm 80$ d.C. coherente con la evidencia cerámica.

\section{Puripica-23}

Corresponde a dos conglomerados y dos recintos aislados compuestos por un total de 15 estructuras circulares entre viviendas y bodegas adosadas (ca. $936 \mathrm{~m}^{2}$ de ocupación). Se ubica también en la planicie superior que domina la quebrada Puripica por la banda sur, hacia el NO del sitio arcaico PU-1. Los recintos muestran sus muros abatidos, construidos con la técnica de doble pared y relleno interior, constituyendo grandes estructuras con diámetros fluctuantes entre 6 a $8 \mathrm{~m}$ (Figuras 2 y 5 ).

En la superficie del sitio se muestreó el entorno del recinto seleccionado para la prueba-1, registrándose escasos fragmentos de tiestos rojos y negros pulidos pertenecientes a la tradición formativa de San Pedro de Atacama. Por otro lado, la existencia de lajas de andesita intrusivas dan cuenta de la producción local de palas de uso variable. Se realizó una prueba cronoestratigráfica en el recinto del extremo NO del sitio del orden de 150x60 $\mathrm{cm}$, identificándose un depósito de ceniza homogéneo (Anexo 1).

De acuerdo a los materiales excavados, la presencia de palas líticas y puntas pedunculadas son 

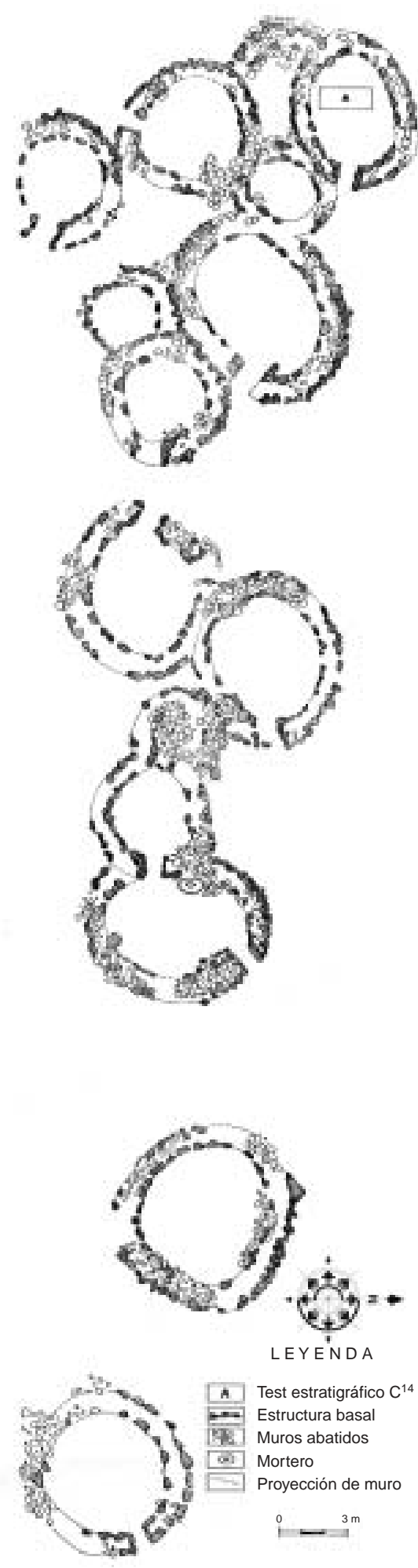

Figura 5. Planta de la aldea Puripica-23.

Plan of Puripica-23 village. parte contextual del sitio, incluyendo el manejo de llamas desde el inicio de la ocupación (coprolitos). Debe señalarse que el uso de obsidiana de calidad se aplicó en artefactos bi y unifaciales, debidamente formatizados (p. ej., puntas de proyectil). Esta selección implicaría traslados a los pisos altoandinos, tal como se manifestó en los sitios anteriores. Con respecto a la cerámica, es dominante el registro de bordes en coma, tiestos café alisados y de los componentes Negro Rojo y Café Pulidos, clásicos de la tradición San Pedro de Atacama. Una muestra de carbón del recinto 1 del inicio de ocupación se dató en $190 \pm 80$ d.C. La similitud de su formato arquitectónico con el asentamiento Tulor-1 es evidente tanto su morfología como en su relación cronológica (Llagostera et al. 1984).

\section{Los Asentamientos Aldeanos de Quebrada Tulán}

\section{Tulán-57}

Se trata de un asentamiento aglomerado complejo, compuesto de cuatro conjuntos localizados en el borde sur de la planicie que domina quebrada Tulán a unos 2.958 msn (Figuras 1 y 6). Precisamente, este es el sitio más cercano a las vertientes que dan lugar al arroyo Tulán, dispuesto, como en Puripica, en el mismo locus de los asentamientos arcaicos tardíos y formativos tempranos $\left(640 \mathrm{~m}^{2}\right.$ de ocupación).

La ocupación se representa con 13 estructuras circulares entre recintos habitacionales y bodegas adosadas, conformando leves montículos, aunque los muros están visibles, constituidos por una matriz de barro con inclusiones de rocas para consolidarlos. Los recintos presentan grandes dimensiones (diámetros entre 3 a $6 \mathrm{~m}$ ), siguiendo específicamente el patrón constructivo de Tulor, observándose una planta homologable a los inicios de Tulor-1, cuando se levantaron los primeros conglomerados separados y que, de acuerdo al posterior crecimiento demográfico, se abigarraron entre sí. En la superficie del sitio se registran escasos restos culturales, con importante presencia de preformas y artefactos tallados en toba Tulán, manos y morteros de hueco extendidos y cónicos.

En TU-57 se excavó un recinto completo, más un testigo y otro bloque recuperado para análisis de flotación. De acuerdo al perfil cronoestratigráfico se identificaron cinco estratos sucesivos en un depó- 


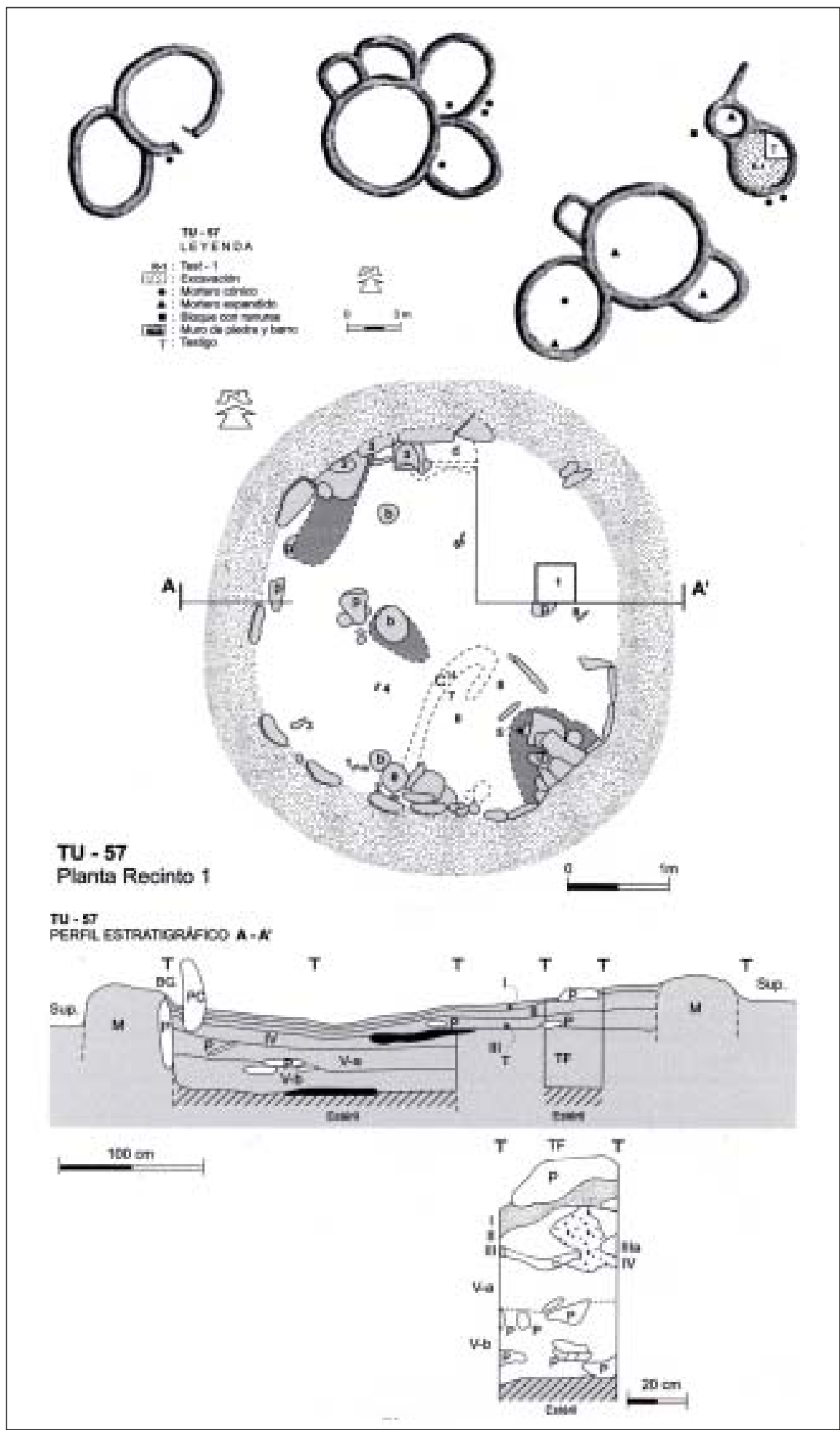

Figura 6. Planta de la aldea Tulán-57. Planta del recinto excavado con el registro del decapado sobre el piso original datado. Perfil A-A' del recinto excavado.

Plan of Tulán-57 village. Plan of the excavated enclosure with the record of decapage on the original dated floor. Profile A-A'of the excavated enclosure. 


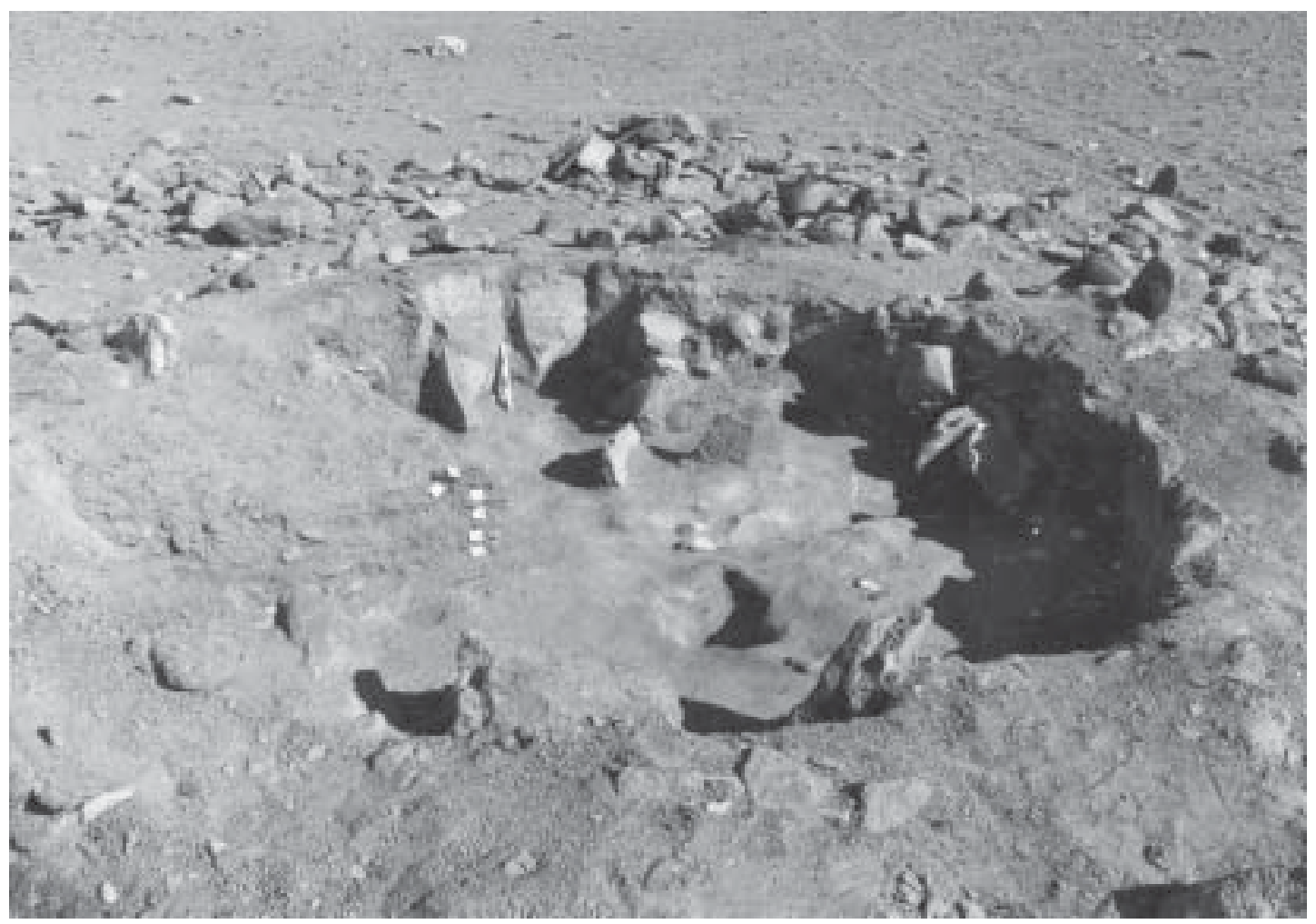

Figura 7. El recinto 1 durante el proceso de excavación (TU-57/R 1).

Compound 1 during excavation (TU-57/R1).

sito decapado del orden de ca. $7 \mathrm{~m}^{2}$ (Figuras 6 y 7). En el Estrato I se identificó un depósito delgado de arena fina plomiza con gravilla gruesa y efectos de deflación con escasos restos culturales (ausencia de marcadores cerámicos). El Estrato II presenta un depósito similar al anterior, aunque con menos gravilla y escasos restos culturales. En el estrato III se identificó un depósito delgado con sedimento blanquecino, escasos restos orgánicos y culturales y bolsón (III-a). El Estrato IV se compone de arena fina plomiza con residuos de ceniza, restos culturales, fogones y desechos de ocupación más intensiva con restos cerámicos de la tradición formativa de San Pedro de Atacama. En el inicio de ocupación se destaca el Estrato V-a con arena fina plomiza-ceniza y gravilla, residuos orgánicos y culturales con potentes restos de ocupación, incluyendo los indicadores cerámicos precedentes en los niveles a y b. El Estrato V-b es un depósito de arena fina con gravilla y restos de cabezales de muros parcialmente abatidos. Durante el inicio de ocupación se utilizaron fogones extendidos asociados a sedimentos calcinados. De acuerdo a la superposición de fogones, habría evidencias de dos niveles ocupacionales vinculados con el inicio y desarrollo clímax de la aldea. De un bolsón, a nivel del piso originario, socavado durante el evento ocupacional inicial, se recobró carbón datado $\mathrm{C}^{14}$ a los $30 \pm 80$ años d.C.

De la excavación referida se registraron 887 especímenes culturales y naturales: cerámica (208 evidencias), lítico (611 evidencias), óseo (32 evidencias), vegetales (6 evidencias), faunístico (6 evidencias), constituyendo una colección del orden de los 9.668 gr (Anexo 1). Los registros líticos suman 67 artefactos formatizados con presencia de puntas de proyectiles y un elenco diversificado de artefactos dedicado a organizar el consumo intramuro y preparación de implementos: cuchillos expeditivos, perforadores generalizados y especializados, raederas, raspadores-muescas y tajadores pesados (Anexo 1). Por otra parte, la presencia de manos de molienda para fines alimenticios y ritualísticos (molienda de pigmento rojo) da cuenta de labores a nivel intramuro. Las palas podrían relacionarse con labores de canalización, mineras y hortícolas en predios limitados en la estrecha caja 
del arroyo. Aunque no se constataron restos de maíces por causas accidentales, hay restos de recolección vegetal (cactáceas: Opuntia sp. y chañar: Geoffroea decorticans). En materia de desechos líticos y lascas no formatizadas se contabilizaron 532 evidencias de las cuales sólo 40 son lascas expeditivas con filos naturales usados, mientras que el resto son desechos percutidos intramuro. La roca más utilizada es la toba Tulán local (297 evidencias) y el basalto y/o andesita (169 evidencias) y en tercer lugar obsidiana (99 evidencias), lo cual significa que el acceso al piso altoandino se mantenía vigente (Anexo 1). Considerando la totalidad del registro lítico, las frecuencias presentan rangos similares entre sí, con accesos equilibrados entre quebrada Tulán y la alta puna (toba Tulán, 207 evidencias; basalto-andesita 192 evidencias, obsidiana 109 evidencias). Sin embargo, una comparación más detallada indica cambios sugerentes. La frecuencia del uso de rocas en el recinto- 1 indica que a comienzos de ocupación (ZET) había un mayor empleo de obsidiana, la que disminuye gradualmente hacia el final de la ocupación (ZETA). En la misma medida, el uso de toba Tulán local se incrementa en los niveles medios a altos (ZEMZETA). Con respecto al basalto, otro recurso foráneo y local a la vez, se le considera en este caso poco indicador de movilidad. Sin embargo, la variable obsidiana es un marcador más seguro, de tal modo que se propone que durante las zonas tempranas y medias (ZET y ZEM) había más contacto con el piso altoandino. De ser correcta esta interpretación, se esperaría que en los momentos en que se constituye la aldea y se procede al manejo de los recursos locales, la ganadería fue la fuente de mayor productividad, incluyendo desplazamientos trashumánticos hacia los pisos forrajeros más extensivos localizados en las tierras altas, al oriente de la quebrada Tulán.

Por otra parte, no se advierte una alta diversidad de rocas, puesto que el uso de sílice, jaspe, mármol y cuarzo es francamente minoritario. En este sentido, tanto el basalto y toba Tulán, de frecuencia significativa, se orientan a artefactos de regular a gran factura con tendencia a soluciones expeditivas, sin excesos de modelación, salvo las aplicaciones de percusión y presión en los filos laterales, entre artefactos derivados de lascas, más que de láminas. En este caso, el bajo índice de láminas establece una clara identidad cultural en un territorio con recursos potenciales en términos de producción de láminas. Por otra parte, la obsidiana es aplicada para artefactos de menor factura, con talla más delicada, tras el formato de funciones específicas como las puntas de proyectil. Se admite que gran parte de los artefactos líticos se ocuparon para labores de consumo (faenamiento y cocina) y preparación de artefactos de hueso y madera. Hay otras rocas de uso menor seleccionadas para funciones específicas, tal como ocurre con la tufa volcánica, cuya textura áspera es muy adecuada para las prácticas de molienda y lajas andesíticas planiformes, usadas exclusivamente para la confección de palas.

Se contabilizó un total de 108 fragmentos cerámicos caracterizados por la presencia dominante de superficies pulidas monocromas: rojiza, ploma, gris, café y negra. La llamada Negra Pulida Clásica de la tradición San Pedro de Atacama, usada con fines funerarios (Tarragó 1989), se ha reconocido desde el comienzo de ocupación (ZET) al nivel medio (ZEM), con escasa frecuencia. Esta vez fue posible asegurar su rol doméstico a raíz de registros fragmentados a nivel del piso ocupacional, tal como se observó en los fondos de cabañas de las aldeas de Puripica. Aquí se confirma su doble rol, toda vez que su patrón ritualístico se identificó a través de una ofrenda de un vaso completo, llamado "tonelito", en un escondrijo ubicado en el cabezal del muro del recinto excavado (Figura 8). Se debe considerar que un tiesto similar fue hallado en un contexto funerario Ciénaga (fase III). Su filiación al comienzo de la fase IV (Quitor) fue situado cronológicamente a los 400 d.C. (Tarragó 1989).

Al considerar los estratos más tempranos (E Va y b) con un "sello" superior no modificado (E IV), se advierte que los tipos cerámicos alisados y pulidos son contemporáneos y aquellos de la tradición San Pedro Negro Pulido se encuentran estrictamente asociados con una base cronológica del orden de los 30 d.C. Por otra parte, esta datación $\mathrm{C}^{14}$ podría indicar que a lo menos el vaso "tonelito" (Forma II/tipo D) podría ser cronometrado inmediatamente post 30 d.C. (Figura 9). Estas formas cilíndricas fueron clasificadas en la fase III y IV (Sequitor y Quitor) de acuerdo a los estudios de Tarragó (1989). De aceptarse que el tiesto referido se acerca a la datación, podría confirmarse el inicio de su distribución durante la fase funeraria Sequitor (100-400 d.C.).

En el registro comentado también se han cons- 

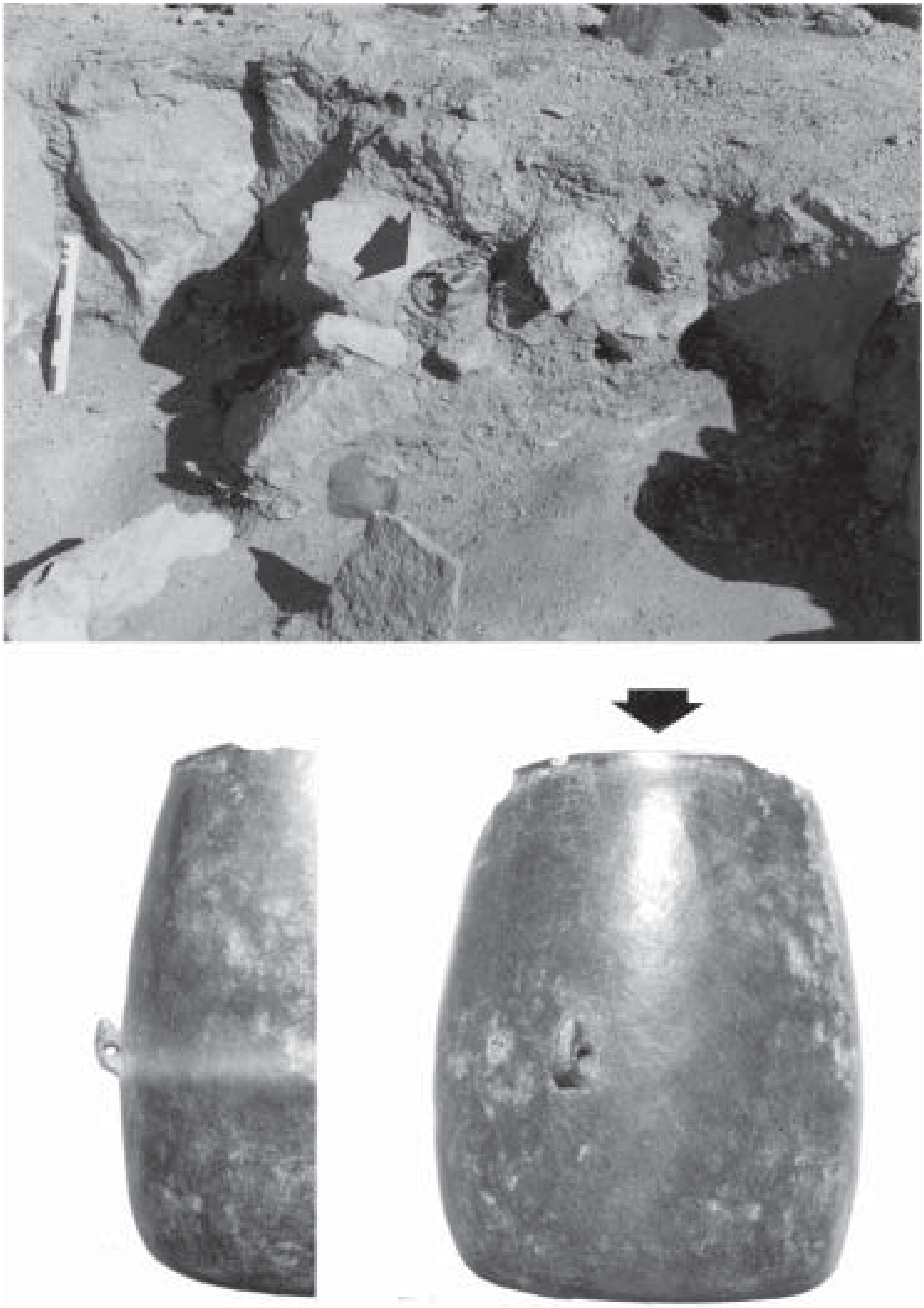

Figura 8. Ubicación de la ofrenda de un vaso tipo “tonelito" pulido clásico en el cabezal del muro abatido parcialmente, durante el final de la ocupación original. Se aprecia el detalle del vaso en perfil y frente.

Location of an offering of a classical polished "tonelito" type vessel on the top of the partially tumbled wall, during the end of the original occupation. Note the detail of the vessel in profile and front view. 


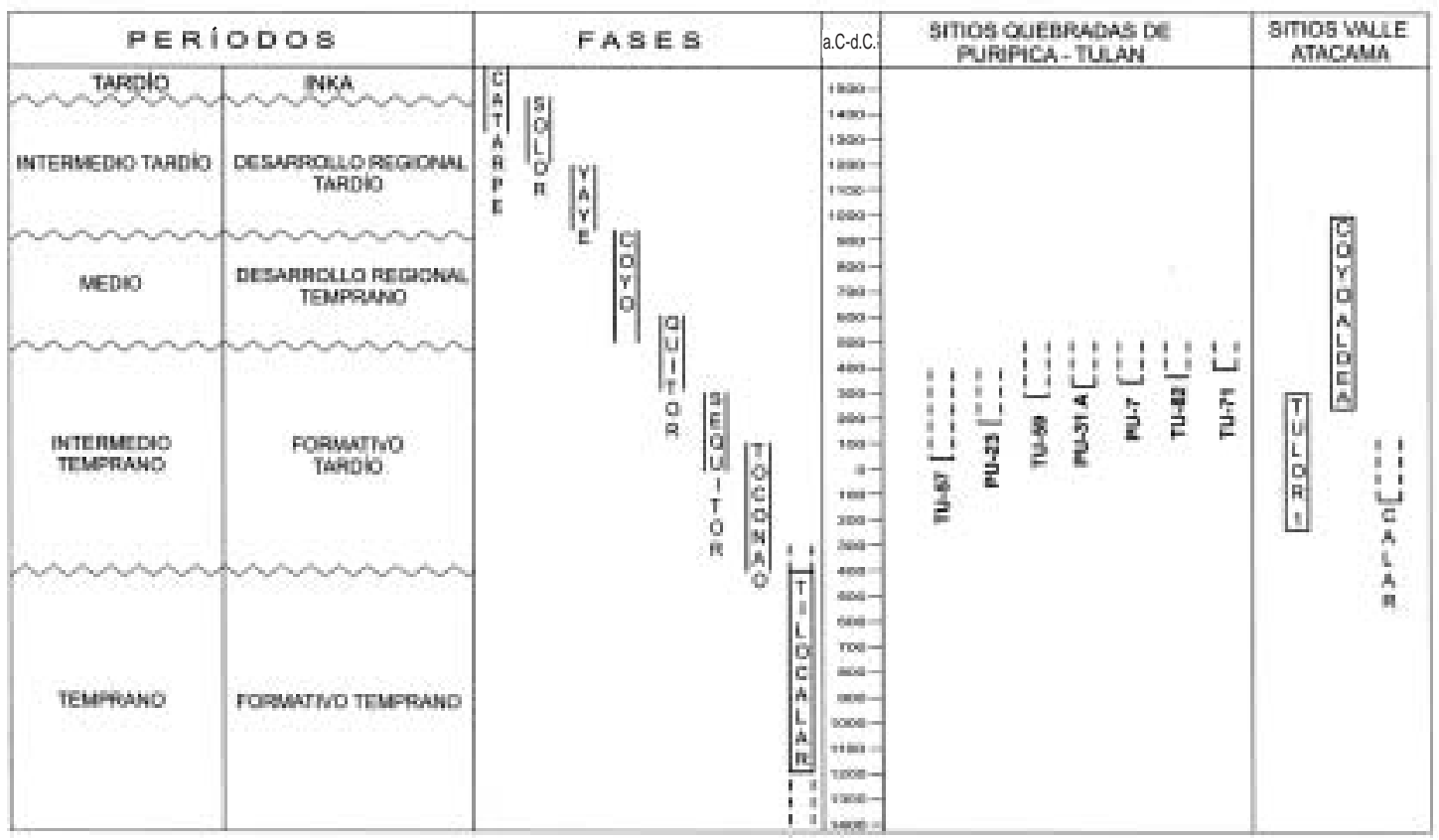

Figura 9. Secuencia de asentamientos del período Formativo Tardío con dataciones radiocarbónicas (cuenca de Atacama). Late Formative Period settlement sequence with radiocarbon dates (Atacama Basin).

tatado restos de camélidos como registro dominante en las tres zonas estratigráficas, con más énfasis durante ZET. La ausencia de restos óseos naturales y modificados durante ZETA refuerza la tesis de baja intensidad criancera. Por otra parte, esta tendencia se confirma con la presencia y uso de coprolitos de llamas, trasladados desde los aleros y corrales identificados sincrónicamente al pie del acantilado aledaño, como combustible para los fogones intramuro localizados exclusivamente durante ZET y ZEM. De ser correcta esta apreciación, se podría sugerir que al final de la ocupación del FTA la actividad ganadera habría disminuido, esta vez, por un incremento de labores agrarias.

Del subproducto camélido se elaboraron artefactos óseos con extremos agudos, con terminaciones y/o uso tendiente al pulimentado distal (textilería?). La ubicación de una tortera, hecha de un fragmento de cerámica negra bruñida típica para el FTA, demuestra que las prácticas de hilado y telar provienen desde el comienzo de la ocupación. Es probable que algunos implementos óseos con cicatrices sean retocadores de artefactos líticos. Por otro lado, la presencia de huesos con cortes, asti- llados y quemados, demostraría labores de consumo intramuro, con una presencia continua y dominante de restos de camélidos, complementados también con una bajísima asistencia de presas de aves y roedores.

El registro minero-metalúrgico es importante en cuanto, al igual que la fase previa Tilocalar, se presenta con restos de minerales de cobre y crisocola/turquesa para la confección de bienes de estatus. Un resto de cobre fundido y laminado podría significar labores locales orientadas a la preparación de lingotes y/o preformas. Siguiendo el patrón del Formativo Temprano, la explotación minero-metalúrgica se habría intercalado en las labores pastoralistas, en especial, en aquellos distritos mineralizados como el área Peine-Tulán.

La presencia entre el material misceláneo de pigmento rojo se ha identificado sobre lascas (ZEM), en manos (ZEM y ZET), también en preformas bifaciales derivadas de lascas gruesas (ZEM), sobre todo en palas reutilizadas (ZET) y fragmentos óseos (ZET); además, en restos de caracol de agua dulce trasandino (ZET), incluyendo 
yunques planos de molienda (ZET), desde el comienzo de ocupación (p. ej., lasca/bolsón-3 y pala/ rasgo-3). Estas múltiples evidencias indican la importancia del color rojo-ocre en la ritualidad aldeana de TU-57, sin relaciones exclusivas con prácticas funerarias (Bibar 1966[1558]). De acuerdo a un análisis químico, una muestra obtenida de pigmento rojo adherido a huesos provenientes de la cercana cueva Tchulin (TU-67) dió cuenta de la aplicación de óxido de fierro, sin restos orgánicos (Martín Grosjean, comunicación personal 1995).

Al examinar el perfil estratigráfico y sus componentes más indicadores, el depósito Va y b se interdigita con el Estrato IV, en cuyo techo se localizan los últimos fogones del patrón doméstico previo. Los estratos tempranos y medios (E-V y IV) se han depositado bajo los cabezales de muro, en un socavado logrado en el momento de la construcción del recinto. Por lo mismo, estos depósitos están dispuestos claramente bajo el nivel estéril de la superficie no modificada del sitio que rodea al recinto (Figura 6). En este sentido, no hay una discordancia tan definida entre los Estratos Va y b, en cuanto representan un depósito homogéneo, de la misma manera como el techo del E V-b se interdigita con lentes del E-IV (ver perfil ampliado del test de flotación en Figura 10). Sin embargo, se observa una discordancia mayor entre los E-I, II y III y el techo del E-IV, caracterizado por niveles muy delgados, asociados a bloques de muros caídos, configurando depósitos tardíos cuando el recinto estaba abandonado y/o parcialmente ocupado, con baja utilidad residencial a raíz de la colmatación del socavado semisubterráneo (Figura 6). No es posible asegurar si ZETA es efectivamente una reocupación tardía no originaria; sin embargo, a lo menos denotaría ciertos cambios productivos. En efecto, se reconoce un descenso notable de la cerámica con tratamiento pulido y bruñido, paralelo a la disminución de actividades ganaderas, de acuerdo al menor registro de huesos de llamas y virtual desaparición de huesos modifi-

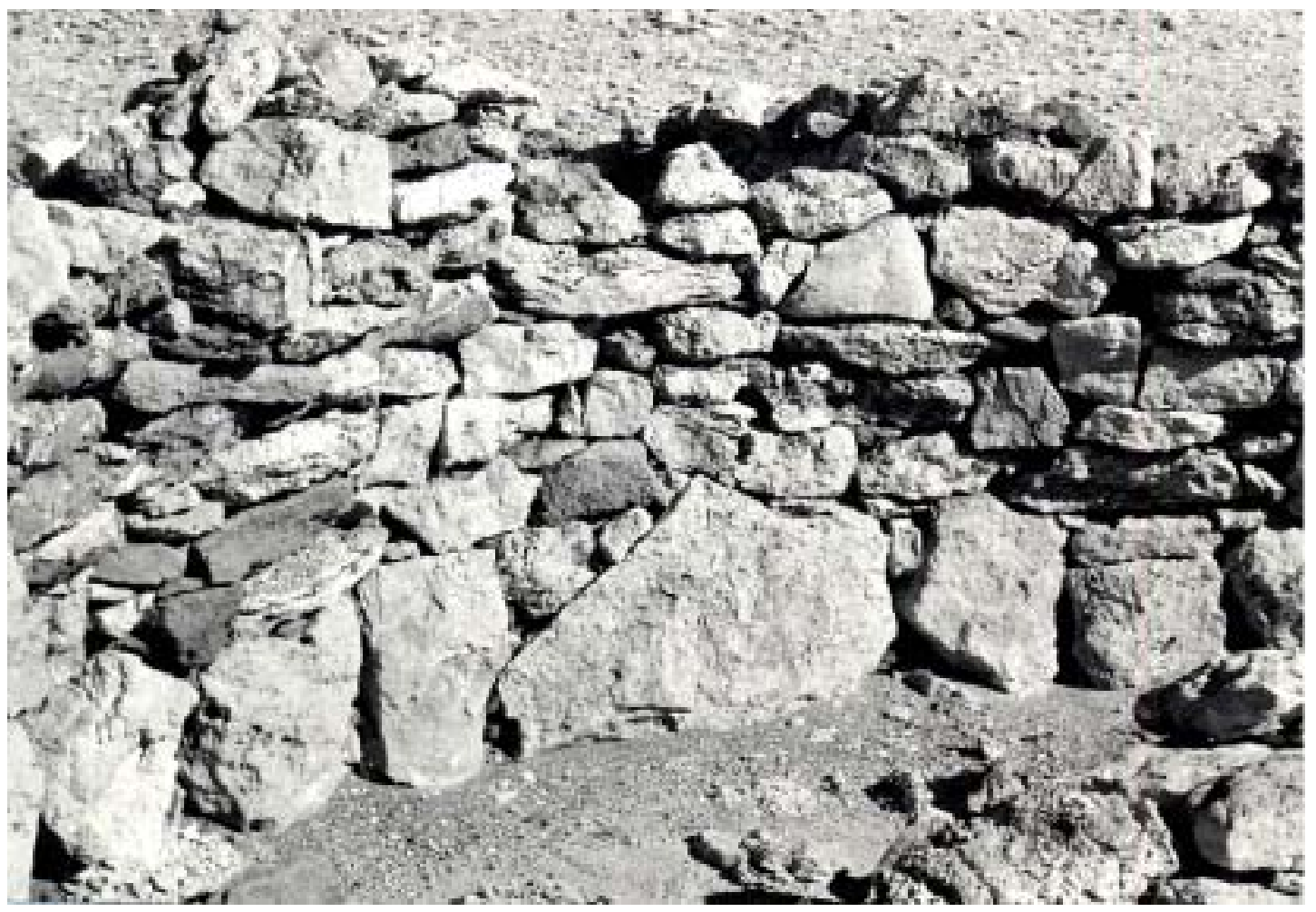

Figura 10. Detalle constructivo de la aldea Tulán-82 con los típicos bloques de mayor volumen empotrados en la base estéril, siguiendo la tradición arquitectónica de la fase Tilocalar.

Construction detail in Tulán-82 village with the typical larger volume blacks embedded in the sterile base, following the Tilocalar. Phase architectural tradition. 
cados y coprolitos de llamas, y la disminución de la explotación minero-metalúrgica. El registro tardío de semillas de chañar indicaría un acercamiento a los oasis piemontanos donde debió intensificarse la labor agrícola, incentivándose un eventual abandono del asentamiento por un hipotético acercamiento al oasis agrario de Tilomonte.

El decapado logrado en la base del E-Vb permitió identificar varios rasgos que guardan relación con las actividades fundacionales vinculadas directamente con el piso ocupacional datado en los 30 años d.C. (Figura 6). Aquí se habrían preparado artefactos de huesos de llamas, desde piezas óseas planas asociadas a restos de diente de camélido y un instrumento específico con extremo aguzado. Se habrían utilizado dos lascas expeditivas una con filo natural usado y la otra con retoque unifacial elaboradas con toba Tulán (rasgo 1). Una acción similar vincula la modificación de restos de camélidos (molar y huesos largos), para la producción de artefactos (rasgo 2). También se habría preparado pintura roja sobre un gran fragmento de pala tabuliforme (andesítica) de bordes gruesos bifaciales. En este sentido, las palas en desuso servían como plataformas multipropósito (rasgo 3). Se localizaron dos fragmentos de cerámica gruesa y pulida como posible materia prima para retomarlas tal como ocurrió con una tortera hecha de un fragmento cerámico (bolsón 2; rasgo 4). Se registró, además, un gran tajador lítico de toba Tulán de cuerpo grueso y pesado ( $316,9 \mathrm{gr})$, bilateral y tabuliforme para acción de golpe cortante (rasgo 5). Otro tajador tabuliforme con filo bifacial-unilateral semicurvado (basalto) está asociado a dos huesos de camélidos adultos y fragmento de cerámica alisada y gruesa (rasgo 6). Se reitera esta labor con un tajador bifacial unilateral recto de basalto (rasgo 7). Un madero cilíndrico cepillado con un extremo algo redondeado de uso no definido completa estas locaciones (rasgo 8).

Con estos antecedentes se propone que durante el inicio de la ocupación se habrían practicado labores artesanales con lascas y tajadores sobre madera y huesos. Esto explicaría el amplio espacio residencial que incluye tanto acciones domésticas de consumo y aquellas relacionadas con la preparación de artefactos. Por otra parte, en el piso original se socavaron seis bolsones o depresiones correspondientes a la ocupación más temprana, vinculadas al levantamiento de postes, bodegas, escondrijos y otros, encubiertos a veces por relle- nos diferenciados y depósitos secundarios. Se verificó la presencia de corpúsculos de carbón, desechos de obsidiana, toba Tulán, restos de roedores, aves, camélidos y fibras de lana (camélido), relacionados con el barrido del piso (bolsón 1). La asociación entre una lasca de obsidiana expeditiva con filo natural usado y una costilla de camélido no modificada significarían intervenciones sobre estas materias primas. El registro de una tortera de cerámica negra bruñida, demostraría que esta reutilización ocurrió sobre el piso original, durante la fase Sequitor, con la datación del comienzo de ocupación del orden de 30 d.C. No se descarta que las prácticas de hilado se hayan realizado a nivel intramuro, desde los inicios, estableciéndose una cerrada relación con las prácticas pastoralista en términos de esquila y preparación de hilados, tal como se reconoce etnográficamente entre los últimos pastores del transecto Peine-Tulán (bolsón 2). El material combustible trasladado desde el exterior se reconoció para la preparación de fogones, debido al encuentro de abundantes coprolitos de llamas, carbón vegetal, leña y posibles fecas con restos de semillas de cactáceas. La presencia de dientes y huesos de llamas indicaría restos de consumo barridos junto a dos trozos de vasijas, incluyendo un Negro Pulido Clásico, propia del FTA y una lasca de toba Tulán expeditiva con filo natural usado. El registro de otra lasca tabuliforme con filo cortante en un lado recto, con pigmento rojo, demostraría que habría una tendencia a utilizar plataformas de artefactos líticos para fines ritualísticos. Sea este registro un acto preparatorio de pintura (paleta), con o sin significado ideológico en sí mismo, lo seguro es que, al no registrarse pictografías en el entorno del sitio, el uso de ocre tanto en términos de funebria como en rituales sobre artefactos y/o piezas líticas, sería un componente muy requerido por los aldeanos del FTA (bolsón 3). Una típica horadación estrecha y cilíndrica, posiblemente usada para la introducción de poste con fines de sustentación de techumbre, se rellenó con materiales del piso original, en especial, con huesos finos de roedores. Este último registro sugiere que éstos fueron atraídos por desechos alimentarios durante posible eventos de ausencia a raíz de las tareas pastoralistas fuera del asentamiento. La presencia de dos lascas expeditivas de basalto con filo natural usado y un desecho de percusión fino al interior del bolsón, demostraría que, en general, sobre el piso se habrían elaborado artefactos líti- 
cos paralelo al reavivamiento de sus filos en torno a tareas artesanales y de preparación de instrumental (bolsón 4). En un socavado poco profundo y longitudinal se muestreó carbón para la determinación $C^{14}$ del comienzo de ocupación (30 \pm 80 años d.C.). Se registraron asociados restos óseos de consumo a nivel intramuro tales como aves y camélido en lo principal.

Se considera, en general, que el uso en Tulán57 de cerámica negra, roja, ploma y café pulida clásica, morteros extendidos y cónicos, puntas pedunculadas con aletas, cuchillos bifaciales tabulares expeditivos, abundante uso de pigmento rojo, palas y microperforadores, son seguros indicadores del FTA. Se suman los restos de camélidos maduros, coprolitos de llamas (fogones), frutos de cactácea y chañar, conchas del piedemonte yungueño y del Pacífico, mineral de cobre y fundido e instrumento de hilado que representan actividades pastoralistas mineras asociadas cercanamente a la datación $\mathrm{C}^{14} 30$ años d.C.

\section{Tulán-59}

Se trata de un conglomerado compuesto por cinco estructuras circulares apegadas a un corral moderno, junto al acantilado ignimbrítico donde se localiza el alero TU-64. Sus recintos presentan diámetros entre los 2 a $3 \mathrm{~m}$ a nivel intramuro, siendo éstos preparados con roca y barro incluidos espacios como bodegas adosadas (ca. $200 \mathrm{~m}^{2}$ de ocupación). Se excavaron dos pruebas cronoestratigráficas en el interior de las estructuras 1 y 2 . Una muestra de carbón del primer recinto de comienzo de ocupación permitió una datación $\mathrm{C}^{14}$ de $270 \pm 50$ d.C. Un detalle constructivo importante es el carácter curvado de los muros similar al patrón Tulor de San Pedro de Atacama y de aquella aldea junto al salar de Atacama localizada en las vegas de Tilocalar (TU-71) con iguales indicadores y dataciones $C^{14}$ sincrónicas (Núñez 1995; Romero 1995).

El análisis cronoestratigráfico presentó fragmentos negros y rojos pulidos de la Tradición San Pedro de Atacama (fase Sequitor). Es muy posible que estos recintos se vinculen con las cercanas ocupaciones pastoralistas datadas sincrónicamente, bajo abrigos rocosos, con actividades de cocina, corrales (coprolitos de llamas) y bloque aislado con petroglifo que representa un motivo geométrico, a unos $20 \mathrm{~m}$ hacia el barranco ignimbrítico. A pesar de la baja densidad ocupacional, estos recintos son homologables al patrón Tulor-1, vinculados con actividades pastoralistas y mineras: puertas estrechas y elevadas, ausencia de ventanas, estructuras adosadas de almacenaje, muros anchos y curvados, techos cónicos y ocupación con tendencia a la agregación. Esta forma de radicación fuera de los oasis de San Pedro de Atacama daría más validez al desarrollo de un proceso expansivo de carácter pecuario en quebrada Tulán.

\section{Tulán-71}

Este asentamiento aglomerado localizado en el borde norte de quebrada Tulán presenta 10 estructuras entre recintos subcirculares y ovoidales (diámetro máximo de $12 \mathrm{~m}$ ), bodegas adosadas y aisladas, con espacios liberados intramuro de notable amplitud, protegidos por un afloramiento rocoso por el borde noroeste (ca. $548 \mathrm{~m}^{2}$ de ocupación). Su ubicación retirada unos $800 \mathrm{~m}$ del curso del arroyo y la identificación de fondos de corrales habla a favor de prácticas pastoralistas (Figura 11). La presencia de cerámica Negra Pulida Clásica desde el comienzo de ocupación se relaciona bien con la datación asociada del orden de 360 d.C. (fase Sequitor y/o inicio fase Quitor).

La prueba-2 aplicada en el recinto- 1 de 2x1 m proporcionó el siguiente material a través de dos estratos con fogones intercalados. El Estrato I se compone de arena eólica con escasa basura. El Estrato II es similar, pero dispuesto entre la base de los fogones y el piso estéril. El registro de un depósito de coprolitos de llamas de un borde de piso de corral ratifica la funcionalidad pastoralista. La datación $\mathrm{C}^{14}$ procede del fogón superior, es decir, la actividad parcial de corral entre fogones ocurrió un poco antes de los 360 d.C. Durante las estaciones húmedas el área de interfluvio suele recubrirse de forraje efímero, pudiendo dar lugar a actividades pastoralistas del patrón "estancia". El elenco cultural sugiere actividades estables con fogones expuestos, depósitos de corrales, utilillaje lítico ad hoc, consumo de alimentos y manejo de tiestos alfareros formativos (Anexo 1).

\section{Tulán-82}

Corresponde a un asentamiento complejo bien conservado, trazado de norte a sur, localizado en el borde de la planicie que domina las vegas de Tilocalar, en el salar de Atacama. Fue registrado 


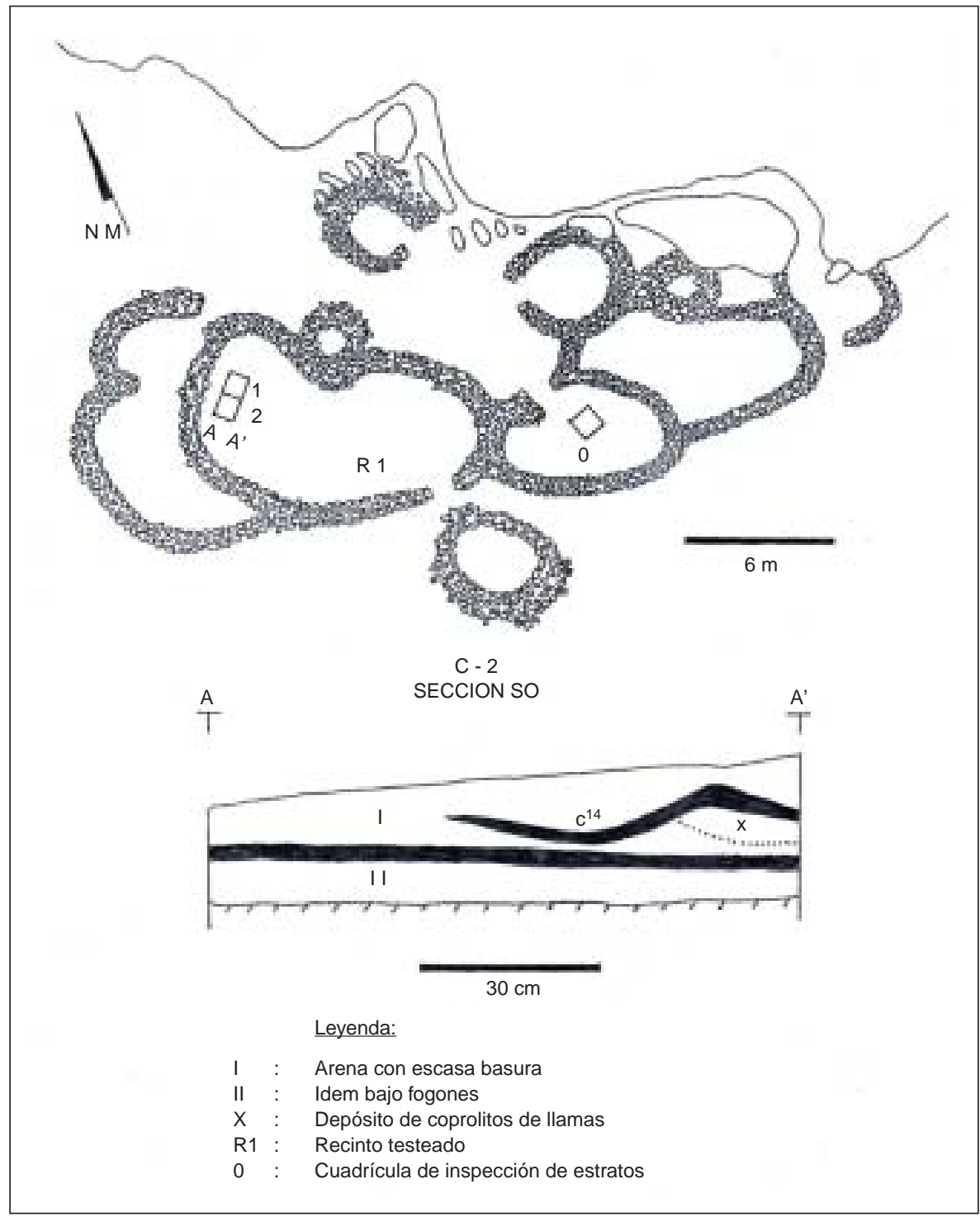

Figura 11. Planta de la aldea Tulán-71 y Perfil del test cronoestratigráfico. Plan of Tulán-71 village and profile of the chronostratigraphic test.

por Le Paige como Tilocalar-2 (Le Paige 1963) y documentado inicialmente por Núñez (1995) y Romero (1995). Se compone de un conglomerado de 49 estructuras entre recintos residenciales, con bodegas adosadas y pasadizos que cubren en conjunto una ocupación total del orden de los $835 \mathrm{~m}^{2}$. Se incluye un gran recinto semicircular en el borde norte separado unos $30 \mathrm{~m}$ con diámetro del orden de los $20 \mathrm{~m}$ asociado a un monolito abatido relacionado a posibles actividades ritualísticas. Se destacan seis recintos mayores con fines residenciales ( 5 a $6 \mathrm{~m}$ de diámetro), aunque en otros tres casos se observan altas concentraciones de mineral de cobre. Los espacios interiores mayores comparten con recintos más pequeños de menos de $1 \mathrm{~m}$ de diámetro entre bodegas originarias y reocupaciones con estructuras menos formatizadas. Los muros están constituidos de bolones costrosos con mortero de barro y se mantienen sus cabezales entre 80 y $100 \mathrm{~cm}$ sobre la superficie, advirtiéndose la típica curvatura interior del patrón Tulor. Por otra parte, sus bodegas demuestran la presencia de techos en falsa bóveda a través de la aplicación de grandes lajas planiformes. El levantamiento de los 
muros se logró con la disposición de bloques basálticos verticales en la base, y otros más reducidos en los niveles medios, con disposición horizontal, hasta arreglar en los cabezales aquellos costrones salobres y calcáreos de menor peso para lograr la curvatura cónica que sostenía los techos con postes y vigas. Se reconoce la técnica constructiva con doble hilada y relleno interior típica del FTA (Figuras 10 y 12). Se realizó un test de 1 $\mathrm{m}^{2}$ donde se identificaron cuatro estratos sucesivos. El Estrato I se compone de sedimento estéril mezclado con ceniza registrados en dos niveles (a y b). En el Estrato II se identificó sedimento fértil con ceniza y registros culturales. En el Estrato III se determinó un depósito de sedimento café fértil con vegetales asociados al bolsón (B) que ruptura el Estrato IV. Finalmente, el Estrato IV se compone de sedimento semifértil comprimido, asociado a escasos residuos de ocupación, como un piso inicial extendido sobre la base estéril (inicio de ocupación). La datación $\mathrm{C}^{14}$ se corresponde con la presencia de cerámica negra pulida clásica y maíz, del orden de los 340 d.C. y, de acuerdo al socavado del bolsón, se entiende que el comienzo de ocupación debió ser algo más temprano (Figura 11).

De la superficie del sitio se ha recuperado una alta diversidad alfarera con distintas implicaciones cronológicas como los componentes Ayquina (Varela et al. 1993) y Dupont (Núñez 1966) del período Intermedio Tardío y los más formativos con tratamientos bruñidos y pulidos en ambas caras, donde se destaca el Negro Pulido Clásico, fragmentos con labios evertidos sin asas, uso de revestido café-rojizo y pastas con desgrasantes gruesos (Romero 1995).

De la prueba cronoestratigráfica 1 (Núñez 1995), localizada junto a una anterior (Romero 1995), se advierte una mayor frecuencia de tiestos negros pulidos clásicos (fase Sequitor y Quitor) en relación a su registro en superficie. Precisamente en la prueba-1 la más alta representación alfarera se corresponde con el componente Negro Pulido Clásico, al interior de la familia pulida de la tradición San Pedro de Atacama (Anexo 1). La presencia de fragmentos tipo Tilocalar con desgrasantes de granos gruesos (cuarzo) podría sugerir que la producción alfarera de TU-82 y aun la arquitectónica podría derivar de la fase anterior Tilocalar, situación que amerita un análisis más detallado.

La datación $\mathrm{C}^{14}$ de 340 d.C. puede representar a las actividades registradas en los Estratos IV, III y II (fase Sequitor terminal y comienzo fase Quitor). De acuerdo a las observaciones de superficie y excavación de prueba, se proponen labores vinculadas con extracción cuprífera (minerales de cobre,

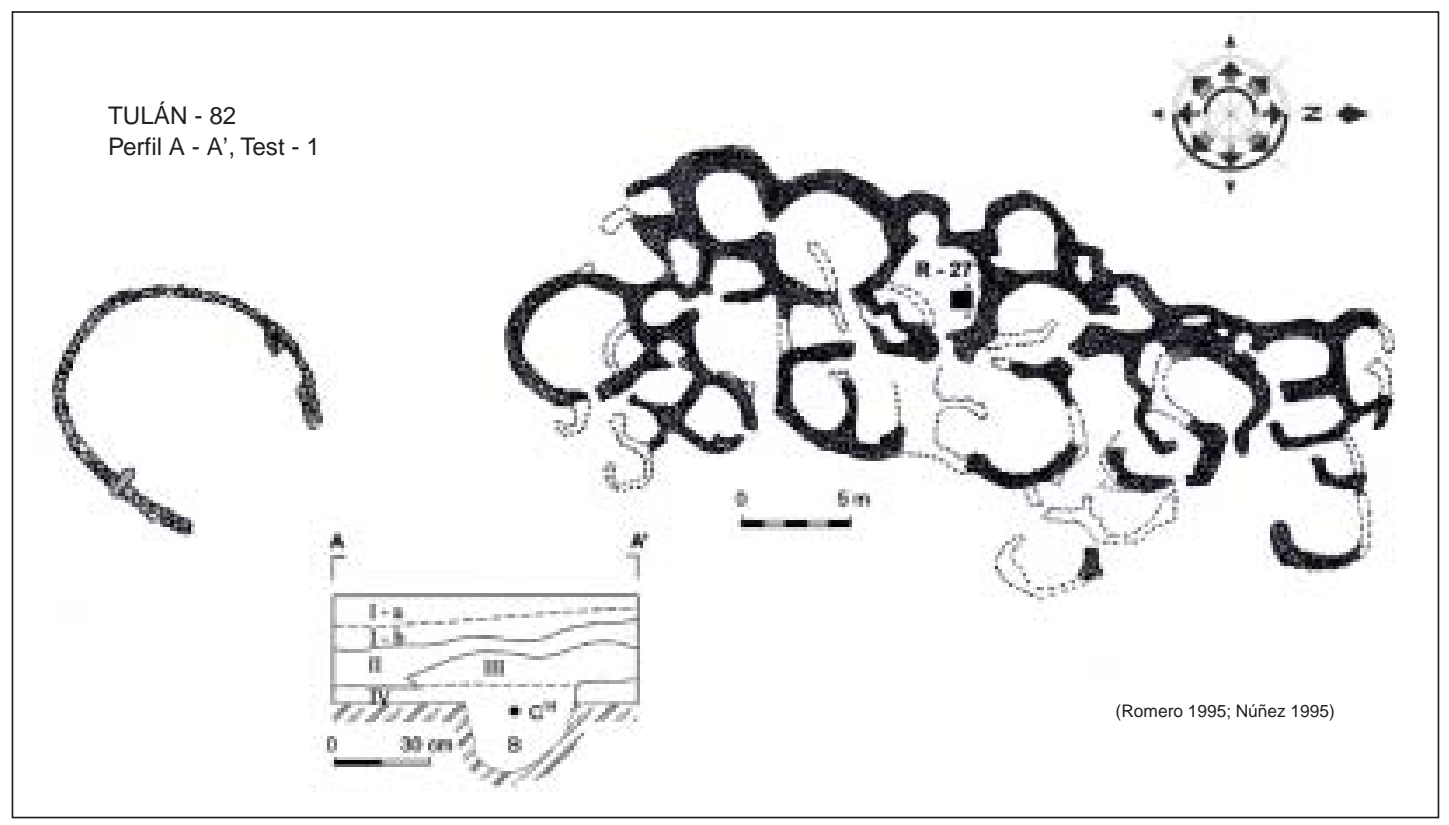

Figura 12. Planta de la aldea Tulán-82 con indicación de la prueba cronoestratigráfica-1 y muestreo radiocarbónico (Estructura 27). Se observa una ampliación del perfil A-A'.

Plan of Tulán-82 village with chronostratigraphic test 1 and the radiocarbonic sample (Structure 27) marked. Profile A-A' is enlarged. 
malaquita y crisocola) localizadas tanto al noreste como al suroeste, cuyas vetas provendrían de la cercanía del pueblo de Peine, a menos de una jornada de traslado. Las actividades de cocina se distinguen por la sucesión de fogones asociados a frecuentes huesos de camélidos maduros.

Por otra parte, las prácticas de almacenamiento y molienda in situ ratifican la diversidad de actividades intramuro. Se suma la textilería a raíz de la presencia de vellones, hilos y fragmentos de textiles (uso de tintura roja y otras). Las tareas de talla lítica local se concentraron en la toba Tulán, basalto y obsidiana, esta última más preferida para la confección de puntas pedunculadas con aletas. Tanto la industria lítica expeditiva como los restos textiles, huesos de llamas, vellones, cuerdas hiladas y alta frecuencia de coprolitos, cueros y pezuñas de llamas, son indicadores de un intenso manejo del recurso pecuario.

Es importante acotar que en las vegas de Tilocalar (ambiente de salar) es imposible reproducir cultivos y frutos de arboledas (p. ej., algarrobales y chañares). Por lo mismo, la presencia de estos frutos, incluyendo cactáceas y maíz, indican que habían articulado estos bienes desde el oasis cercano de Tilomonte a menos de una jornada de distancia. Las vegas referidas son un espacio rico en forraje de uso exclusivamente ganadero, acorde con la alta frecuencia de coprolitos de llamas, en estricta relación con el actual uso etnográfico.

De acuerdo a la orientación pastoralista exclusiva de este sitio, sus artefactos más recurrentes guardan relación con actividades de caza, microperforación con artefactos finos de sílice sobre cuentas y cueros, de faenamiento y rituales (Figura 13).

\section{Conclusiones}

Los análisis tanto de la materialidad funeraria, productiva y constructiva, además de los indicadores ideológicos, ratifican que la sociedad agraria de los oasis de San Pedro de Atacama alcanzó un clímax demográfico y sociocultural en el FTA (400 a.C.-400 d.C.), constatado a través de la alta frecuencia y complejidad de sus asentamientos y cementerios (Hernández 1999; Llagostera y Costa 1999; Le Paige 1963; Noel 1992; Tarragó 1989). Hasta ahora el desarrollo previo de asentamientos precursores menos frecuentes, pero de alta complejidad, correspondientes a la fase Tilocalar del Formativo Temprano se ha localizado hacia el borde sureste de la cuenca de Atacama (Núñez 1992,
1999; Figura 1). Sin embargo, la transición entre eventos formativos tempranos y tardíos en los oasis de San Pedro de Atacama merece una acuciosa investigación, por cuanto no parece razonable concluir que la emergencia de sociedades pastoralistas aldeanas y templarias tan complejas, con respuestas maduras y bien formatizadas, sean exclusivas de la quebrada de Tulán (Núñez et al. 2004, 2005).

La necesidad de lograr un equilibrio, durante el FTA, entre la producción agraria de los oasis piemontanos y la explotación pastoralista del hinterland forrajero, desde la alta puna ca. $4.000 \mathrm{msm}$ a las vegas del salar ca. 2.200 msm, habría estimulado un régimen político de expansión hacia los enclaves ganaderos ya explotados durante el Formativo Temprano. En este sentido, en el FTA la intensificación y demarcación de espacios de explotación dinámica y complementaria habrían estimulado la fundación de aldeas pastoralistas, como los casos descritos correspondientes a las quebradas de Puripica y Tulán, desde los oasis de San Pedro de Atacama, con mayor énfasis en arroyos permanentes, cuyos recursos naturales se correlacionan mejor con el manejo ganadero. ¿Hubo continuidad entre la fase Tilocalar (1.400-400 a.C.) y los asentamientos formativos tardíos del transecto Tulán (400 a.C.-400 d.C.)? Aunque este tema será investigado, por ahora sólo se sugiere que estas aldeas responderían al control sociopolítico ejercido desde los oasis de San Pedro de Atacama.

El registro de asentamientos FTA estructurados, complejos y conglomerados, con recintos circulares y bodegaje adosado, localizados entre los ayllus agrarios y arboledas de los oasis de San Pedro de Atacama, tales como las aldeas datadas $\mathrm{C}^{14}$ de Tulor, Coyo y la cercana de Calar (Graffan 1995; Llagostera et al. 1984; Orellana 1988-9), nos permiten hipotetizar que existió aquí un manejo agrario eficiente, que involucró a una optimización de suelos y regadíos en las tierras bajas $(2.200 \mathrm{msm})$. Sin embargo, un buen número de asentamientos aglomerados homologables a los descritos no han sido datados ni documentados a lo largo de toda la cuenca de Atacama (Le Paige 1963), de tal modo que aspectos distribucionales más conspicuos aún están pendientes, en donde los casos de Puripica y Tulán no deberían ser los únicos ni los más representativos de esta expansión aldeana pastoralista desde los oasis referidos (Figura 9).

Se postula, en consecuencia, que la intensificación de la producción durante el FTA involucró 
(a)

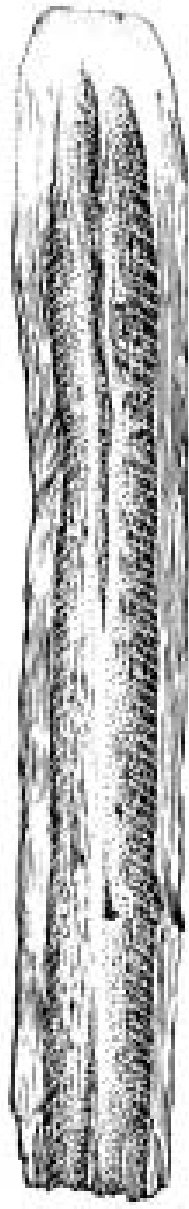

(g)

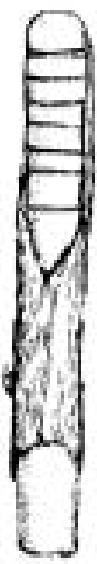

(b)
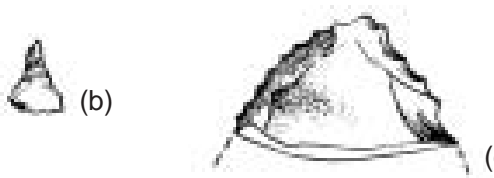

(c)

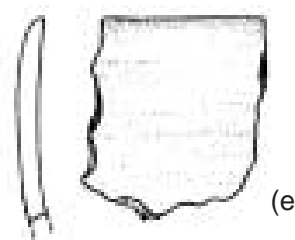

(e)
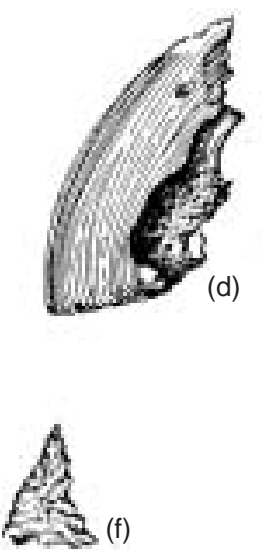

Escala $1: 1$

(h)

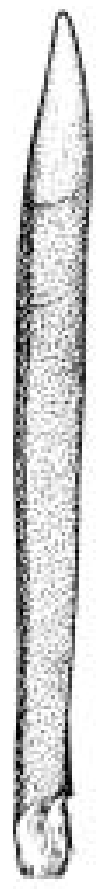

(i)

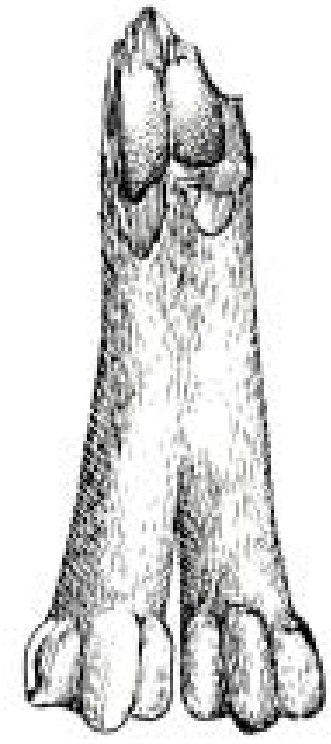

(j)

Figura 13. Conjunto de artefactos representativos del climax ocupacional de la aldea Tulán-82. (a) punta pedunculada de obsidiana para actividades de caza (E II); (b) microperforador en vértice para trabajar cuentas y cueros (E II); (c) raedera basáltica monofacial en vértice para faenamiento (E II); (d) pezuña de camélido, objeto ritualístico (E II); (e) borde delgado de cerámica Negra Pulido clásico, de uso doméstico (E II); (f) microcuchillo asimétrico bifacial presionado, en vértice para faenamiento (E II); (g) artefacto óseo de camélido con extremo distal rebajado como penetrador y/o desangrador para faenamiento (E IV); (h) rama cilíndrica con incisiones transversales de uso desconocido (E III superior); (i) artefacto óseo con extremo distal agudo con funciones de punzón y/o artesanal (E III superior); (j) extremo distal percutido de tibia de llama adulta (E III superior).

Assemblage of artifacts representative of the occupational climax of Tulan-82 village. (a) hunting stemmed obsidian point (E II); (b) pointed silice microperforator applied to breads and leathers (E II); (c) microfacial basaltic convergent side scrager for butchering (E II); (d) camelid hoof, ritual object (E II); (e) fragment of classic Black Burnished pottery for domestic use (E II); (f); pointed bifacial asimetric micro-knife for butchering (E II); $(g)$ bone artifact with worked distal section, used as boring or bleed tools in butchering activities (E IV); (h) wooden stick with transversal incisions, unknown use; (i) bone tools with point distal section, used as boring tool for handcraft (E III upper); (j) percuted distal section of a tibia of adult llama (EIII upper). 
un régimen de expansión pastoralista desde los oasis de San Pedro de Atacama y, en este sentido, la importancia de las aldeas marginales presentadas aquí, es que provienen de los extremos norte y sur de la cuenca de Atacama, sugiriendo que efectivamente esta expansión fue recurrente en ambientes quebradeños más útiles en términos forrajeros. Varios indicadores cronológicos, productivos, artefactuales y ecológicos dan cuenta de la uniformidad y pertenencia a tradiciones y organizaciones comunes: (a) estructuras tendientes a la aglomeración con plantas circulares, bodegas adosadas y muros anchos de adobones de barro e hiladas de piedra con mortero, con variables de acuerdo a los recursos locales, incluida la típica curvatura de los muros y techos tronco-cónicos (patrón Tulor), además de pisos socavados y perforados a modo de bolsones para diversos usos (cocinas, bodegas, escondrijos y huecos de postes); (b) la expansión ocupacional quebradeña $(3.000 \mathrm{msm})$ presenta asentamientos menores y disgregados en relación a los complejos aldeanos de los oasis de San Pedro de Atacama, a raíz de los desplazamientos trashumánticos, a juzgar por la dinámica ganadera y más acceso a materia y bienes exóticos (p. ej., minería y obsidiana); (c) aunque se presentan restos alimenticios de recolección arbórea y cultivos de maíz, éstos proceden de la conexión con los oasis piemontanos, mientras que la mayor evidencia de huesos y coprolitos de llamas asegura que la explotación pastoralista fue dominante. La tendencia en términos de mantención de llamas parece radicar en las cajas de las quebradas, junto a refugios sincrónicos bajo roca asociados a corrales; (d) la presencia de martillos, minerales de cobre para fundido y ornato (óxidos de cobre/crisocola/turquesa) y piezas ritualísticas fundidas de cobre y plata sugieren una especialización minero-metalúrgica asociada a las prácticas pastoralistas derivadas de la misma orientación socioeconómica de la fase previa Tilocalar (Formativo Temprano); (e) la presencia de tiestos cerámicos pulidos del FTA, recurrentes en los oasis de San Pedro de Atacama, se reconoce en todos los sitios de pastoreo quebradeños analizados, en especial, de la tradición San Pedro Negro Pulido Clásico. La ritualidad implicada en las ofrendas de contenedores, como el registrado en el escondrijo de un muro (TU-57), permite asumir que vasos tan emblemáticos y comunes en la funebria de San Pedro de Atacama, eran parte sustancial de ciertos rituales al interior de las unidades domésticas en una de las quebradas pastoralistas más alejadas del sur.

Desde un punto de vista cronológico, un total de siete dataciones (carbón) procesadas en Beta Analitic indican que estos asentamientos, localizados en los bordes de la cuenca, iniciaron las ocupaciones FTA desde los 30 d.C., y se asume que su secuencia ocupacional no superó el techo cronológico del orden de los 400-500 d.C. (dataciones no calibradas), cubriendo las fases funerarias Sequitor y Quitor (Figura 9). Para los efectos de correlacionar la disolución y/o abandono de los asentamientos aldeanos FTA, se ha propuesto que un régimen de aridez asociado al avance de dunas habría remitido a las ocupaciones formativas hacia cotas más altas de los ayllus de San Pedro de Atacama, acorde a las observaciones realizadas en Tulor-1 (Llagostera y Costa 1999). Esta afirmación no se relaciona con nuestra propuesta en el sentido que durante la expansión aldeana aquí tratada se habrían desarrollado eventos con condiciones húmedas favorables, de modo que el acceso hacia aguas arriba podría vincularse con el desarrollo de práticas de regadío canalizado, asociado al climax agrícola de los oasis.

Una de las características principales de las aldeas alejadas de los oasis de San Pedro de Atacama es la presencia de estructuras apegadas, usadas para almacenamiento, asociada a un crecimiento agregado y gradual de las unidades domésticas. En la misma medida que el proceso de intensificación agrario se focalizó en la explotación maicera a lo largo de los oasis, en la periferia más forrajera se estimuló la crianza de llamas a nivel de acumulación de excedentes. El incremento de las prácticas de almacenaje, circulación de excedentes, más dispersión ocupacional dependiente y reproducción de desigualdad social, advierte que esta expansión debió ser conducida por una elite que controló el destino de los recursos explotados y que organizó el territorio de acuerdo a patrones laborales y ritualísticos (Harris 1968). Se trata de lograr un orden demográfico y laboral en donde los asentamientos más dinámicos asumen la explotación de territorios socialmente marginales, más pecuarios que agrarios (Nocete 2001; Núñez 1995).

Se concluye que mientras las labores agrarias en ambientes desérticos tiene límites de regadío y calidad de suelos en espacios fijos, con prácticas 
laborales especializadas y estables asociadas a elite local con estructuras jerárquicas y centralizadas, la explotación de espacios pecuarios fue más fragmentaria, móvil, demográficamente segregada y políticamente dispersa, con instalaciones comparativamente de menor cuantía en términos de densidad constructiva. Sometidos los enclaves pecuarios a controles desde las cabeceras sociopolíticas de los oasis piemontanos, al interior de relaciones de dependencia, la ampliación de los excedentes pastoralistas ocurrió paralelamente al incremento de la explotación minero-metalúrgica exigidas por castas que, al parecer, ya interactuaban bajo un modelo de poder hereditario.

En efecto, la cercanía o lejanía de las fuentes cupríferas en relación a los asentamientos agrarios y pecuarios, no fue un límite para la intensificación de la producción de excedentes, esta vez de mayor jerarquía. Es más, la explotación minerometalúrgica generó redes viales y complejos sistemas de apoyo logístico e introdujo esta variable de mayor retorno económico en términos de intercambio, frente a la fragilidad del manejo del recurso renovable agroganadero bajo un ideal de reproducción económica integrada. La circulación de bienes ritualísticos metálicos y de ornamentación estimuló gradualmente las prácticas de más caravaneo e intercambio intra y extracomarcano con notables cambios que incidieron en estratificación, prestigio y división social del trabajo en relación con el régimen más exploratorio y colonizador de la fase anterior Tilocalar (Lull 1983; Núñez 1992, 1999). De allí que no sea errado sugerir que la expansión aldeana a los bordes de la cuenca de Atacama es la oportunidad en que la "marginalidad" pecuaria contribuyó al incremento de la riqueza pecuaria y minera, esto es, al prestigio regional de la elite de los oasis de San Pedro de Atacama.

El proceso de intensificación subyacente en esta propuesta, implica labores cada vez más especializadas destinadas a privilegiar la explotación de aquellos bienes más competitivos en el marco de intercambio e integración fronteriza. Este proceso habría alcanzado logros óptimos a juzgar por el acceso a bienes foráneos a través de redes sociales de larga distancia (flujo caravanero), como un medio para acceder a recursos exóticos (p. ej., cebil), para un territorio árido con gentes capacitadas a través del tráfico para superar crisis alimentarias en espacios de difícil predicción subsistencial (Mathers 1986;
Núñez 1995). En este orden, el rol del transporte caravanero, asociado a la producción especializada de bienes ganaderos, agrarios, metalúrgicos y costeños facilitó la política de incorporación macrorregional de bienes y recursos complementarios.

A este respecto, el manejo de las menas de cobre acompañó precisamente a las necesidades expansivas aquí referidas. Si bien este proceso productivo es independiente del manejo agropecuario e hídrico, se trata de un recurso que exigió ser administrado a través de intensas exploraciones y explotaciones tanto de cobre para fundido como para ornato y culto. En cuanto sociedades estratificadas, el control de la productividad cuprífera otorgó más jerarquía a las elites a nivel de irradiación regional, al punto que el tráfico de bienes de estatus, desde las aldeas del FTA, creó las condiciones de prestigio necesarias para posteriormente atraer e insertarse en los circuitos de interacción con el estado Tiwanaku.

Si bien se acentuó el carácter pecuario de la expansión aldeana, debe indicarse que los registros tienden a confirmar que la presencia de camélidos salvajes consumidos, pervivientes de la tradición arcaica, fue importante para asegurar y regular la producción ganadera durante eventos transicionales y formativos. Los hábitos de movilidad arcaica persistieron en términos de asegurar presas cazadas paralelos a la dinámica pastoralista trashumántica. Se sabe que los rebaños de llamas retornan a cotas bajas durante la estación invernal resolviéndose los límites climáticos de altura a través del retorno a refugios más cálidos, tal como se aprecia con el manejo pastoralista etnográfico, precisamente tanto en las quebradas de Puripica y Tulán (Núñez 2000; Serracino y Stehberg 1974, 1975). Hasta hoy se reconoce que en los mismos espacios de crianza y movilidad transectual se advierte una alta disponibilidad de fauna silvestre útil para sostener la dualidad caza-pastoralismo, tal como se ha observado sincrónicamente en el altiplano central (Hastorf et al. 2002).

Por otra parte, durante el período FTA se ha planteado que las aldeas agrarias de San Pedro de Atacama se asocian a densos cementerios que han constituido hasta ahora la documentación más cuantiosa de la cultura material (Tarragó 1989). Sin embargo, no se reconocen similares evidencias en las aldeas sincrónicas registradas en los extremos de la cuenca de Atacama. ¿Es que el proceso de 
expansión pecuaria y minera implicaba retornos a las aldeas-cabeceras de los oasis de San Pedro de Atacama, donde sólo allí se ejercían los rituales funerarios? Puesto que las jerarquías sociopolíticas radicaban allí: ¿Acaso sólo en estos oasis piemontanos ocurrían los actos ritualizados de mayor trascendencia?

En suma, desde un punto de vista teórico se ha propuesto que el desarrollo de crecimiento y presión demográfica debieron estimular procesos de intensificación (Kirch 1984), en un marco de creciente complejidad socioproductiva (Chapman 1975, 1978; Gilman 1976; Harrison 1985). Los datos aún preliminares derivados de asentamientos y residuos habitacionales indican que durante el FTA existió un régimen expansivo desde los oasis de San Pedro de Atacama hacia su hinterland pecuario, a cargo de una elite local que estableció un equilibrio necesario entre la producción recolectable, agraria, pecuaria, minero-metalúrgica y bienes de larga distancia (p. ej., conchas del Pacífico y agua dulce del NOA). La integración de estos excedentes, tanto domésticos como de estatus, fue un medio exitoso para una mayor estabilidad política y crecimiento económico, paralelo a la creación de redes de circulación e intercambio caravaneros más recurrentes intra y extracomarcano, creándose un espacio atacameño prestigioso inserto en el escenario del Centro Sur Andino, a pesar de la reducida escala de sus recursos naturales.

Agradecimientos: Los datos inéditos de terreno del presente artículo fueron registrados durante nuestros proyectos FONDECYT 1017-86 y 1930022, junto a la colega I. Cartajena de la Universidad de Chile, con la colaboración de C. Becker, J. Espada y H. Mamani, arqueólogos titulados en la Universidad de Chile, Nacional de Jujuy y Complutense de Madrid, respectivamente. El procesamiento analítico y editorial de estos datos se debe al aporte del proyecto en curso FONDECYT 1026316. Un reconocimiento especial al apoyo interdisciplinario del Dr. Martín Grosjean invitado por el proyecto complementario FONDECYT 1020316 y a los pastores de Peine y Puripica por sus enseñanzas de tantos años juntos; finalmente a la revisión editorial de Chungara.

\section{Referencias Citadas}

Abbot, M.B., M.W. Binford, M. Brenner y K.R. Kolts 1997 A $3500{ }^{14} \mathrm{C}$ high resolution record of water-level changes in lake Titicaca, Bolivia/Perú. Quaternary Research 47:109-180

Agüero, C., M. Uribe y O. Reyes

1995 Nuevos sitios para la ocupación formativa del Valle de Quillagua. Boletín de la Sociedad Chilena de Arqueología 21:24-27.

Ayala, P. y M. Uribe

2003 La cerámica Wankarani y una primera aproximación a su relación con el periodo formativo del norte grande de Chile. Textos Antropológicos 14(2):7-29.

Benavente, A.

1982 Chiuchiu 200. Una comunidad pastora temprana en la provincia del Loa (II Región) IX Congreso Nacional de Arqueología, pp. 75-94, La Serena.

Berenguer, J., A. Deza, A. Román y A. Llagostera 1980 La secuencia de Myriam Tarragó para San Pedro de Atacama: Un test por termoluminiscencia. Revista Chilena de Antropología 5:17-54.

Bibar, G. de

1966 [1558] Crónica y Relación Copiosa y Verdadera de los Reinos de Chile. Fondo Histórico y Bibliográfico J.T. Medina, Santiago.

Carrasco, C.

2002 Las industrias líticas de Quillagua durante el período formativo en el contexto del Norte Grande. Estudios Atacameños 22:33-57.
Castro, V., C. Aldunate, J. Berenguer, L. Cornejo, C. Sinclaire y V. Varela

1994 Relaciones entre el noroeste argentino y el norte de Chile: El sitio 02 TU 002 vegas de Turi. En Taller de Costa a Selva, editado por M.E. Albeck, Instituto Interdisciplinario de Tilcara, Provincia de Jujuy, Argentina.

Chapman, R.W.

1975 Economy and society within later prehistotric Iberia : A new framework. Tesis Doctoral Universidad de Cambridge. 1978 The evidence for prehistoric water central in south-eastSpain. Journal Arid Environments 1:261-274.

1991 La Formación de las Sociedades Complejas. Traducido por C. Rihuele. Editorial Crítica, Barcelona.

Graffan, G.

1995 Preliminary report: Aldea de Coyo. Manuscrito suministrado al IIAM-UCN (Manuscrito).

Gilman, A.

1976 Bronce age dynamic in southeast Spain dialectical. Anthropological 1:307-319.

Gilman, A. y J.B. Thornes

1985 Land-use and Prehistoric in Southeast Spain. Allen y Unwin, Londres.

Grosjean, M.

2002 The little ince age in the South Central Andes: Climate changes during the last 1000 years. (Manuscrito suministrado al Proyecto FONDECYT 1020360). 
Harris, $M$.

1968 The Rise of Anthropological Theory. Routledge and Kegan Paul, London.

Harrison, R.J.

1985 The "policultivo ganadero" at the secondary products revolution in Spanish agricultural 5000-1000 BC. Proceedings of the Prehistoruc Society 51:75-102.

Hastorf, C., M. Bandy, W. Whitehead y L. Steadman 2002 El periodo formativo en Chiripa, Bolivia. Textos Antropológicos 13 (1-2): 17-91.

Hernández. J.C.

1999 Inventario y Yacimientos Arqueológicos de la Comuna de San Pedro de Atacama, II Región, Chile. 3 vols. Universidad Católica del Norte.

Le Paige, G.

1963 Archivo de sitios arqueológicos. IIAM-UCN. Manuscrito.

Llul, V.

1983 La "Cultura" de El Argar. Un modelo para el Estudio de las Formaciones Económico-Sociales Prehistóricas. Akal, Madrid.

Lynch, T. y L. Núñez

1994 Nuevas evidencias inkas entre Collahuasi y Riofrío (I y II regiones del Norte de Chile). Estudios Atacameños 11:145-164

Llagostera, A., A.M. Baron y L. Bravo 1984 Investigaciones arqueológicas en Tulor. Estudios Atacameños 7:133-150.

Llagostera, A. y M.A. Costa

1999 Patrones de asentamientos en la época agroalfarera de San Pedro de Atacama (Norte de Chile). Estudios Atacameños 17:175-206.

Martínez, M.I.

1989 Una revisión Crítica de la Prehistoria Española: La Edad del Bronce como Paradigma. Eitorial Veintiuno, España.

Mathers, C.

1986 Regional development and interaction in SE Spain (6000-1000 DC). Tesis Doctoral University of Sheffield.

Molina, F.

1983 Prehistoria de Granada. Don Quijote, Granada.

Noel, M.

1992 Prospección de sitios arqueológicos en la localidad de San Pedro de Atacama. Práctica Profesional, Universidad de Chile, Santiago de Chile. Manuscrito.

Nocete, $F$.

2001 Relaciones y contradicciones centro/periferia en el valle de Guadalquivir. En Tercer Milenio Antes de Nuestra Era. Ed. Bellatera Arqueología, Barcelona.

Núñez, L.

1966 Arqueología del rectángulo Loa-Camiña: contextos y secuencia culturales. En Actas del XXXVII Congreso Internacional de Americanistas, pp. 3-11, Mar del Plata.

1974 Agricultura prehistórica en los andes meridionales. Editorial Orbe, Santiago de Chile.

1978 L'evolution millenaire d'une vallée: Peuplement et ressource à Tarapacá. Annales Economies Societés Civilisations. Extrait des numeros 5-6: 906-920. Paris.

1982 Temprana emergencia de sedentarismo en el desierto chileno: proyecto Caserones. Chungara 9:80-122.

1992 Emergencia de complejidad y arquitectura jerarquizada en la Puna de Atacama: Las evidencias del sitio
Tulán-54. En Taller de Costa a Selva, editado por M.E. Albeck, pp. 85-115, Instituto Interdisciplinario de Tilcara, Argentina.

1995 Evolución de la ocupación y organización del espacio atacameño. En Agua, Ocupación del Espacio y Economía Campesina en la Región Atacameña, editado por P. Pourrut y L. Núñez, pp. 18-60. ORSTOM-Universidad Católica del Norte, Antofagasta.

1999 Fase Tilocalar: Nuevas evidencias formativas en la Puna de Atacama (norte de Chile). En Formativo Sudamericano. Homenaje a A.R. González y B. Meggers, editado por P. Ledergerber-Crespo, pp. 227-242. Departamento de Antropología, Museo de Historia Natural, Smithsonian Institution, Washington.

Núñez, L., I. Cartajena, C. Carrasco, R. de Souza y M. Grosjean 2004 Transición entre el Arcaico Tardío al Formativo Temprano en la Puna de Atacama. Manuscrito. ICA, Santiago de Chile.

Núñez, L., M. Grosjean, B. Messerli y H. Shreler

1997 Cambios ambientales Holocénicos en la Puna de Atacama y sus implicancias paleoclimáticas. Estudios Atacameños 12:31-40.

Núñez, L. y T. Dillehay

1979 Movilidad Giratoria, Armonía Social y Desarrollo en los Andes Meridionales: Patrones de Tráfico e Interacción Económica. Universidad Católica del Norte.

Núñez, L., C. Agüero, B. Cases y P. de Souza

2003 El campamento minero Chuquicamata-2 y la expansión cuprífera prehispánica en el Desierto de Atacama. Estudios Atacameños 25:7-34.

Núñez, L., I. Cartajena y M. Grosjean

1999 Un ecorrefugio oportunístico en la puna de Atacama durante eventos áridos del Holoceno Medio. Estudios Atacameños 17:125-174.

Núñez, L., I. Cartajena, M. Grosjean, C. Carrasco, P. de Souza 2005 Transición del Arcaico Tardío al Formativo Temprano en la cuenca de Atacama: Emergencia de complejidad sociocultural en la subárea circumpuneña. Informe de Avance, año ,3 Vol. I, II y III. Manuscrito. Proyecto FONDECYT 1020316.

Núñez Srytrová, M.K.

2000 Movimiento y Voces en Peine. Tesis para optar al Grado de Licenciado en Antropología y título de Antropólogo Social, Escuela de Antropología, Universidad Academia Humanismo Cristiano, Santiago de Chile.

Orellana, M.

1988-9 Los tipos de artefactos tempranos el Calar y su contexto aldeano. Paleoetnológica. Centro Argentino de Etnología Americana, pp. 73-78, Buenos Aires.

Raffino, R.

1973 Las aldeas del Formativo Inferior de la quebrada del Toro (Salta, Argentina). Estudios Atacameños 5:64-108.

Romero, A.

1995 Tilocalar: Vida aldeana temprana a través de la cerámica superficial y rasgos arquitectónicos. Práctica Profesional, Departamento de Antropología, Universidad de Chile. Manuscrito.

Sayago, J.M., M.M. Sampietro y M. Caria.

2001 Anomalía climática meridional sobre las culturas del formativo y su relación con los futuros cambios climáticos en el Noroeste Argentino. Actas de la III Reunión Nacio- 
nal y I del Mercosur sobre Geología Ambiental y Ordenación del Territorio, Mar del Plata (Manuscrito).

Sayago, J.M., M.M. Sampietro, M. Caria y M.M. Collantes 2002 Paleoclimatic changes and human crisis in Northwest Argentina during the European medieval warm period. En Quaternary Climatic Changes and Environmental Crisis in the Mediterranean Region, editado por M.B. Ruiz, M. Dorado, A. Valdeolmillos, M.J. Gill, T. Bardajali, U. de Bustamante e I. Martínez, pp. 1-7, Madrid.

Serracino, G.

1976 Tulor-4: cuatro pozos de sondeo. Estudios Atacameños 4: 24-31.

Serracino, G. y R. Stehberg

1974 Investigaciones arqueológicas en Guatín, San Pedro de Atacama. Estudios Atacameños 2:7-10.

1975 La vida pastoril en la precordillera andina (Guatín San Pedro de Atacama, Chile). Estudios Atacameños 3:81-89.

Sinclaire, C., M. Uribe, P. Ayala y J. González

1997 La alfarería del período formativo en el Loa Superior: Sistematización y tipología. Actas del XIV Congreso Internacional de Arqueología Chilena, pp. 285-314, Copiapó.
Stovel, E.M.

1997 Habitacional Analysis and Cultural Contact at Coyo Aldea, Northern Chile: The surface deposits. Thesis of Master. State University of New York at Binghampton.

Tarragó, M.

1968 Secuencias culturales de la etapa agroalfarera de San Pedro de Atacama (Chile). En Actas y Memorias del XXX-

VII Congreso Internacional de Americanistas, vol. 2, pp. 119-145, Buenos Aires.

1989 Contribución al Conocimiento Arqueológico de las Poblaciones de los Oasis de San Pedro de Atacama en Relación con los Otros Pueblos Púnenos, en Especial al Sector Septentrional del Valle Calchaquí. Tesis Doctoral, Universidad Nacional de Rosario, Rosario.

Varela, V., M. Uribe y L. Adan

1993 La cerámica arqueológica del sitio 02TU001: Pukara de Turi. Actas del XII Congreso de Arqueología Chilena. Tomo I, 4:107-122. Museo Regional de la Araucanía, Temuco.

Wheler, J., R. Cardozza y E. Pozzi

1977 Estudio provisional de la fauna de las capas II y III de Telamachay. Revista del Museo Nacional, tomo 43:97-102. 
